\title{
State capacity and military conflict
}

\author{
Gennaioli, Nicola ; Voth, Hans-Joachim
}

\begin{abstract}
Powerful, centralized states controlling a large share of national income only begin to appear in Europe after 1500. We build a model that explains their emergence in response to the increasing importance of money for military success. When fiscal resources are not crucial for winning wars, the threat of external conflict stifles state-building. As finance becomes critical, internally cohesive states invest in state capacity while divided states rationally drop out of the competition, causing divergence. We emphasize the role of the "Military Revolution", a sequence of technological innovations that transformed armed conflict. Using data from 374 battles, we investigate empirically both the importance of money for military success and patterns of state-building in early modern Europe. The evidence is consistent with the predictions of our model.
\end{abstract}

DOI: https://doi.org/10.1093/restud/rdv019

Posted at the Zurich Open Repository and Archive, University of Zurich

ZORA URL: https://doi.org/10.5167/uzh-113243

Journal Article

Published Version

Originally published at:

Gennaioli, Nicola; Voth, Hans-Joachim (2015). State capacity and military conflict. Review of Economic Studies, 82(4):1409-1448.

DOI: https://doi.org/10.1093/restud/rdv019 


\title{
State Capacity and Military Conflict
}

\author{
NICOLA GENNAIOLI \\ Bocconi University and IGIER \\ and \\ HANS-JOACHIM VOTH \\ Zurich University and UBS Center
}

First version received November 2013; final version accepted October 2014 (Eds.)

\begin{abstract}
Powerful, centralized states controlling a large share of national income only begin to appear in Europe after 1500. We build a model that explains their emergence in response to the increasing importance of money for military success. When fiscal resources are not crucial for winning wars, the threat of external conflict stifles state-building. As finance becomes critical, internally cohesive states invest in state capacity while divided states rationally drop out of the competition, causing divergence. We emphasize the role of the "Military Revolution", a sequence of technological innovations that transformed armed conflict. Using data from 374 battles, we investigate empirically both the importance of money for military success and patterns of state-building in early modern Europe. The evidence is consistent with the predictions of our model.
\end{abstract}

Key words: State capacity, Taxation, Military conflict, Fiscal resources, Military Revolution, War, centralization

JEL Codes: D72, F50, H56, H50, N43

\section{INTRODUCTION}

Capable states cannot be taken for granted. States as we know them today only appear after 1500 in Europe. Earlier European rulers possessed limited tax powers; there was no professional bureaucracy; armies were largely composed of mercenaries; and powerful elites were often above the law (Tilly, 1990). Within three short centuries, however, European powers laid the foundations for modern states, especially by surging ahead of the rest of the world in terms of fiscal capacity.

The leading explanation for this rapid transition emphasizes warfare. Tilly (1990) famously argued that "states made war, and war made states". Because the ability to finance war was key for survival, armed conflict forced monarchs to create effective fiscal infrastructures. Empirically, Besley and Persson (2009) show that countries with a belligerent past have greater fiscal capacity today. To explain this fact, they propose a model in which war is a common interest public good that facilitates investments in state-building (Besley and Persson, 2011).

This perspective helps to explain the coexistence of frequent warfare and growing state capacity. At the same time, four important issues remain. First, warfare was already frequent 
before 1600 , but states mostly failed to develop. ${ }^{1}$ Why do modern states only emerge in a small corner of the Eurasian landmass after 1500 ? Secondly, the growth in state capacity was highly uneven. Britain or France built stronger and bigger states; others such as Spain or Austria fell behind; and some, like Poland, disappeared altogether. While war boosted state-building in some countries, it had smaller or opposite effects in others. The literature on state capacity is currently silent on divergence. Thirdly, warfare during the period of initial state-building (1600-1800) was rarely a common-interest public good. Instead, the "sport of kings" was often a private good for princes in pursuit of glory and personal power. Fourthly, wars are not exogenous events; rulers decide to fight. Military capability influences this decision. Thus, having a strong state may be a cause (instead of a consequence) of war.

In this article, we address these issues by developing a model in which two contending rulers invest in state-building, taking the risk of war into account. State building consists of centralizing the tax system, side-lining domestic power holders. This increases a ruler's control over revenue collection and boosts future tax revenues, but incurs a cost (buying off or fighting local princes). Military conflict is financed with taxes and redistributes fiscal revenues from the losing ruler to the winning one.

War's impact on state-building in our model depends on two factors - the importance of money for military success and initial fragmentation. When the importance of money in war is low, our model implies that — contrary to Tilly's hypothesis and Besley and Persson's model—military conflict dampens state-building (compared to a peaceful world). In this case, both contenders are similarly likely to win the war, regardless of their fiscal revenues. As a result, the richer ruler risks losing fiscal revenues in a war. This increases incentives for poorer rulers to attack. Warfare is frequent but the incentive to raise fiscal capacity is low.

When money is important for military success, the possibility of armed conflict causes strong divergence in state-building. Now, the odds of winning a war are stacked in favour of the richer state. As a result, divided states that find it costly to centralize rationally drop out of the competition; their chances of success are too low. Cohesive states instead engage in statebuilding and will also attack divided ones. Warfare is still frequent, but now it coexists with the consolidation of strong, cohesive states; weak, divided ones gradually lose out. Eventually, a "race to the top" emerges, with all powers building state capacity as they compete more and more in fiscal and military terms. ${ }^{2}$

We confront the predictions of our model with data on military success and state-building in Europe after 1500. Using data on 374 battles, we measure the extent to which the "military revolution" transformed the key factors for success on the battlefield. We show that financial resources became increasingly important for military strength. We also test for interaction effects between fragmentation and the importance of money for military success. As the influence of fiscal revenue on military outcomes grew, more homogenous states disproportionately increased their revenue collection ability. Crucially, we find that as competition between European powers intensified, weaker states became more and more likely to fall behind, both compared to other powers and in absolute terms - reducing their investment in fiscal capacity and witnessing actual declines in tax pressure. This is consistent with our mechanism for divergence in state-building.

1. For example, hunter-gatherer communities registered high rates of violent death (Clark, 2007), but did not engage in state-building on any significant scale.

2. We also show in Section 5.1 that in our model, good institutions are complementary to state-building because they reduce domestic opposition to centralization. A ruler engaged in state-building has stronger incentives to strengthen the constraints on the executive (in the spirit of Acemoglu, 2005), in line with the historical fact that growing state capacity often went hand-in-hand with stronger institutions (Dincecco, 2009). 
TABLE 1

War frequency in Europe

\begin{tabular}{lccc}
\hline Century & $\begin{array}{c}\text { Number } \\
\text { of wars }\end{array}$ & $\begin{array}{c}\text { Average } \\
\text { duration (years) }\end{array}$ & $\begin{array}{c}\text { Percentage years } \\
\text { under warfare (\%) }\end{array}$ \\
\hline 16 th & 34 & 1.6 & 95 \\
17 th & 29 & 1.7 & 94 \\
18 th & 17 & 1 & 78 \\
19 th & 20 & 0.4 & 40 \\
20 th & 15 & 0.4 & 53 \\
\hline
\end{tabular}

Source: Tilly 1990.

Our research relates to recent work on state capacity (Besley and Persson, 2009, 2011; Dincecco, 2009). We also contribute to the empirical literature on taxation and the growth of European states after 1500. The article that is closest in spirit to ours is Karaman and Pamuk (2013). The arrangements that allowed representative assemblies and the ruler to strike a bargain in general is explored in Hoffman and Rosenthal (1997). Our work also relates to recent research on economic incentives, political interests, and interstate conflict. Martin et al. (2008), and Rohner et al. (2013) study the link between war and trade. Jackson and Morelli (2007) study the political factors leading to military conflict. Alesina and Spolaore (2005) analyse how the risk of war affects the optimal size of countries. Spolaore and Wacziarg (2009) examine the link between war and genetic distance. ${ }^{3}$

Relative to the existing literature, we make the following main contributions: First, we build a simple model that investigates the effects of war on state capacity building in a twoplayer setup. This allows us to clarify the conditions under which we should expect greater war threats to aid state-building. One key result is that the link need not be positive-a belligerent environment can lead to lower state-building. Secondly, we compile quantitative measures of the rising importance of fiscal revenues for military success, and demonstrate how they interacted with internal fragmentation to shape the rise of fiscal capacity across European powers.

\section{HISTORICAL BACKGROUND AND CONTEXT}

War was common in early modern Europe. Between 1500 and 1700, a Great Power war was underway in $95 \%$ of all years, as shown in Table 1 (Levy, 1983). And yet, numerous wars were also fought elsewhere and in earlier periods. Europe saw extended conflict during the medieval period, from the Reconquista in Spain to the Hundred Years War between England and France and to innumerable wars between Italian city states. Similarly, China experienced prolonged conflict during the "warring states period", between 475 BC and 221 BC, and Bali in the pre-colonial era saw frequent wars (Hui, 2005; Nordholt, 2010). In neither medieval Europe, nor Bali, nor early China did frequent warfare coincide with the creation of highly capable and centralized states. Why did "war make states" in Europe after 1500, but fail to do so elsewhere?

Our answer to this puzzle is that aggressive state-building was shaped by an interaction between European political starting conditions and changes in military technology, the socalled "Military Revolution". Before describing it in more detail, we briefly summarize our explanandum - the rise in state capacity in early modern Europe.

3. Our contribution also touches on the vast literature studying the economic consequences of institutions. (Acemoglu et al., 2001, 2005; Acemoglu, 2005; Delong and Shleifer, 1993; Greif, 1993; North, 1989). This literature does not explicitly consider the role of external conflict, but it sometimes argues that war can overcome domestic agency problems that stand in the way of better institutions (Acemoglu and Robinson, 2006). 


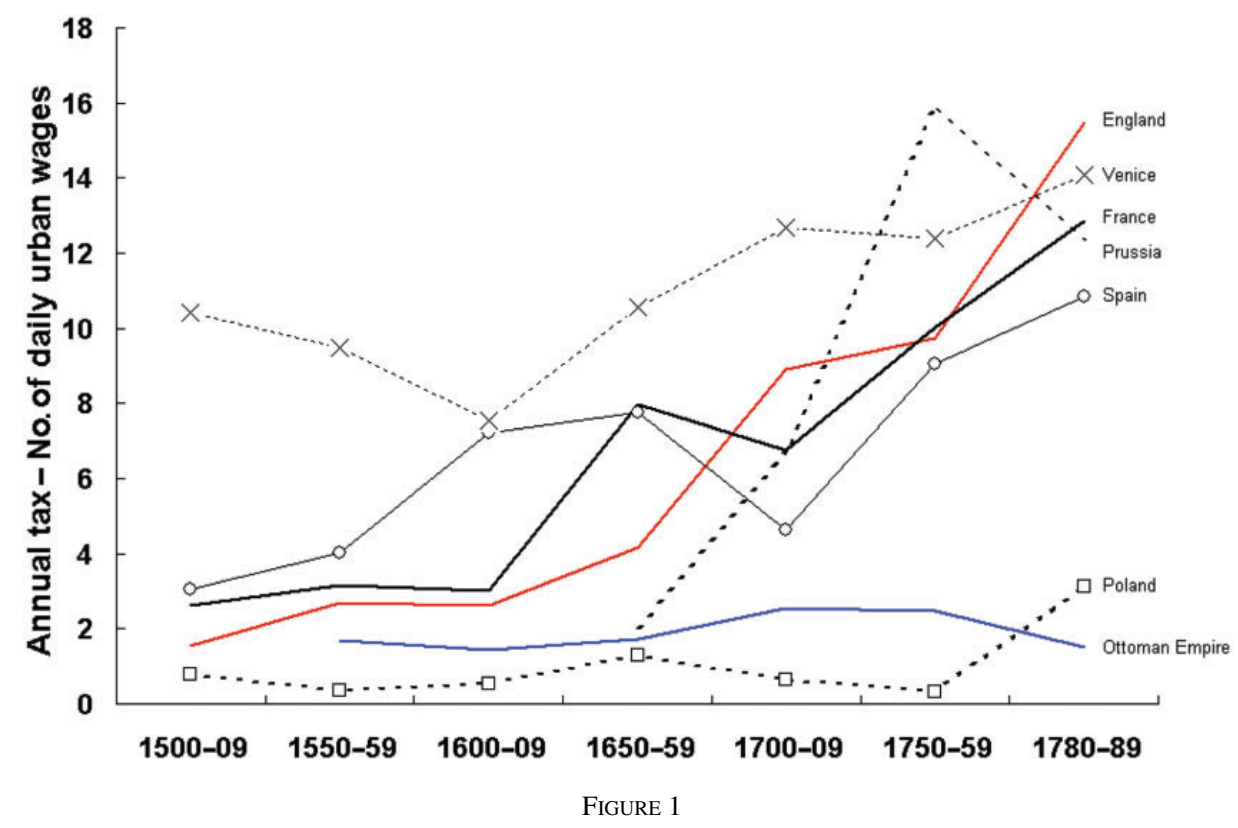

Fiscal capacity in Europe, 1500-1789

Source: Karaman and Pamuk (2010); European State Finance Database.

\subsection{The rise of state capacity}

Two features of state-building in Europe after 1500 stand out-a large increase overall, and growing divergence in the cross-section. Figure 2 plots tax pressure in major European powers over time (which we define as the per capita tax take as a multiple of the country-specific urban wage). Tax pressure in England increased 10-fold, from 1.5 to 15.5; in the Ottoman Empire, on the other hand, it actually fell from 1.7 to $1.5{ }^{4}$ In combination, differences in tax pressure and growth increased variation in the cross-section of European powers considerably. In 1500, Poland's total revenue was half of England's. In 1780, it was equivalent to only 5\%. The overall tax take grew strongly because of both population growth and rising tax pressure. In 1500, the combined revenue for all major European powers was 214 tons p.a. Some 280 years later, this had increased by a factor of twenty, to 4400 tons p.a.

New administrative structures facilitated the rise in income. Medieval rulers largely financed their expenses with domain income (Landers, 2003). After 1500, this became increasingly impossible. To raise sufficient revenue, states needed to levy taxes on a substantial scale. This entailed administrative capacity-building and reform. For example, by 1780, Britain had centralized collection of excise and customs taxes, and was about to introduce the first successful income tax in history. France, on the other hand, continued to use tax farming for both direct and indirect taxes all the way up to the French Revolution (Bonney, 1981), and numerous tax exemptions hamstrung attempts to raise revenue. Nonetheless, it succeeded in raising tax pressure.

Changes in tax collection were part of a broader pattern of administrative reforms. Old privileges in composite states increasingly came under attack, but the pace and success of reforms

4. The value of silver declined, but only gradually. The real increase was still by a factor of more than 13 (Hamilton, 1934) 
TABLE 2

Army size in early modern Europe (in 1000s)

\begin{tabular}{|c|c|c|c|c|c|c|c|c|c|}
\hline & \multicolumn{3}{|c|}{1550} & \multicolumn{3}{|c|}{1700} & \multicolumn{3}{|c|}{1780} \\
\hline & Army & Navy & Total & Army & Navy & Total & Army & Navy & Total \\
\hline England & 41 & 25 & 66 & 76 & 115 & 191 & 79 & 109 & 188 \\
\hline France & 43 & 14 & 57 & 224 & 118 & 34 & 183 & 85 & 268 \\
\hline Dutch Republic & & & & 90 & 86 & 176 & 27 & 22 & 49 \\
\hline Spain & 145 & 18 & 163 & 37 & 26 & 63 & 64 & 62 & 126 \\
\hline Austria & 9 & 0 & 9 & 62 & 0 & 62 & 253 & 0 & 253 \\
\hline Prussia & & & & 37 & 0 & 37 & 181 & 0 & 181 \\
\hline Russia & & & & 52 & 0 & 52 & 408 & 19 & 427 \\
\hline Ottoman Empire & 90 & 50 & 140 & 130 & 30 & 160 & 120 & 30 & 150 \\
\hline
\end{tabular}

Source: Karaman and Pamuk (2010).

varied greatly. Prussia, after conquering Silesia from Austria in 1740 , more than doubled annual tax collection there-a success that is generally attributed to the use of salaried officials instead of tax farmers, and to the suppression of the Silesian Estates that had previously represented regional interests (Kuzmics and Axtmann, 2007). Spain, on the other hand, largely failed to reduce the fragmentation of its internal market, or to extend taxation beyond the Castilian heartland (Elliott, 1963). Reforms in Poland foundered on the unanimity principle in the sejm, the assembly of nobles.

\subsection{The "Military Revolution"}

The use of gunpowder was a turning point for military technology. The spread of cannon after 1400 meant that medieval walls could be destroyed quickly. Fortresses that had withstood yearlong sieges in the Middle Ages could fall within hours. In response, Italian military engineers devised a new type of fortification-the trace italienne. It consisted of earthen bulwarks, covered by bricks, which could withstand cannon fire. These new fortifications were immensely costly to build. ${ }^{5}$ The existence of numerous strongpoints meant that wars often dragged on for long periods of time-winning a battle was no longer enough to control a territory. ${ }^{6}$

The introduction of standing armies also added to rising costs. Due to the need for firearms training, states began to organize, equip, and drill soldiers, effectively investing in their human capital. Starting with William of Nassau's reforms during the Dutch rebellion, soldiers were garrisoned and trained continuously. In combination, these changes drove what some historians have called a "Military Revolution" (Roberts, 1956; Parker, 1996)—war became much more costly because of technological change, growing army size, and increasing professionalization.

Military capacity also grew over time, but diverged sharply between different powers (Table 2). At one end of the spectrum, England's armed forces tripled in size between 1550 and 1780 . France's army increased by a factor of five, and Austria's, by a factor of 28. In contrast, Poland was partitioned out of existence as a result of military impotence caused by internal strife and fiscal weakness.

5. The fortress of Besancon was so expensive that when informed of the total cost, Louis XIV allegedly asked if they were made of gold (Parker, 1996).

6. Roger Boyle, the British soldier and statesman observed in the 1670s (Parker, 1996): "Battells do not now decide national quarrels, and expose countries to the pillage of conquerors, as formerly. For we make war more like foxes, more than lyons; and you will have 20 sieges for one battell." [original spelling] 
At the same time, states began to organize permanent navies. While the English navy beat the Spanish Armada in 1588 with an assortment of converted merchant vessels, navies after 1650 became highly professionalized, with large numbers of warships kept in readiness for the next conflict. Investments in naval dockyards, victualling yards, and ships were costly. Even smaller ships in the English navy of the 18th century cost more than the largest industrial companies had in capital (Brewer, 1990).

After 1500, the business of war was increasingly transacted in cash, and not in feudal dues Landers (2003). This could mean that overall costs rose less than cash expenditures, but this is unlikely - indirect social costs probably grew with war frequency and army size. The late Middle Ages and the early modern period also saw greater use of debt financing. On average, $80 \%$ and more of government expenditure would regularly be devoted to military costs. In wartime, military spending alone would often exceed tax revenue. As a result, money arguably became the prime determinant of military success. As the 16th-century soldier and diplomat, Don Bernardino de Mendoza, put it "victory will go to whoever possesses the last escudo" (Parker, 1996).

\subsection{Spoils of victory}

European states not only fought with great frequency; they also redistributed resources from losers to winners. This took three main forms - conquests of territory within Europe, transfers of overseas possessions, and war indemnities. At its most extreme, vanquished states vanished from the map, as did Poland. Even in less extreme cases, territorial transfers could be substantial. In the 42 main peace settlements in Europe between 1500 and 1780, some 20.6 million square kilometers were redistributed - equivalent to $14 \%$ of the earth's land surface. ${ }^{7}$ Conquests in Europe like Silesia, Alsace-Lorraine, and the Duchy of Milan provided substantial tax revenues to their new rulers, as did the transfer of massive overseas territories like Canada.

In the long run, the newly incorporated territories were often taxed according to the new ruler's fiscal system (Prussia doubled the tax revenue from Silesia). In the shorter term, however, the existing tax infrastructure was used by the occupying power. Revenues could be substantialFrederick the Great extracted 55-82 million Thaler from occupied Saxony, Mecklenburg, and Pomerania during the Seven Years War, enough to cover between 1/3 and 1/2 of the cost of the war (Szabo, 2013). Similarly, in redistributed colonial possessions, the new rulers typically benefitted from pre-existing investments in productive assets (like sugar plantations) and tax infrastructure. Finally, war indemnities produced substantial revenues as well. These did not constitute the wholesale seizing of another state's revenue base, but a transfer of resources accumulated as a result of earlier, effective taxation. Again, these could be high, such as the 5 million Riksdaler received by Sweden at the end of the Thirty Years War (Lee, 1991).

\section{THE BASIC MODEL}

We now present a model of the link between state-building and the military revolution. Section 3 illustrates the role of centralization and a ruler's decision to raise fiscal capacity when there is no external war threat. External war is introduced in Section 4.

7. This is based on our own calculations. We did not count the initial conquest of Latin America by Spain, but focused on peace settlements as a result of wars fought in Europe (including against the Ottoman Empire). 


\subsection{Production}

There are three dates $t=0,1,2$. A country consists of a measure 1 of identical districts $i \in[0,1]$ located on a unit circle, each of which is inhabited by a density 1 of agents who are risk neutral and do not discount the future. Agents obtain utility by consuming the only perishable good produced in the economy. At $t=1,2$, an agent can undertake either local $(l)$ or market $(m)$ production. ${ }^{8}$ Local production yields output $A_{l}$ and occurs in an agent's own district. Market production is more profitable, it yields $A_{m}>A_{l}$, but requires the agent to carry out some steps of the production process such as input purchases in a neighbouring district (e.g. the left or right adjacent one). Agents can also engage in home production $(h)$, the least profitable activity $\left(A_{h}<A_{l}\right)$. If a share $n_{x}$ of agents undertakes activity $x=l, m, h$, where $n_{m}+n_{l}+n_{h}=1$, the country's total output is:

$$
Y=n_{m} A_{m}+n_{l} A_{l}+n_{h} A_{h}
$$

Output is maximal when everybody produces for the market $\left(n_{m}=1\right)$.

\subsection{State-building, taxation, and output}

A self-interested ruler finances his expenditures using his domain income $D>0$ and taxes. There are no financial markets. ${ }^{9}$ The ruler can tax local and market production. Home production cannot be taxed. The equilibrium pattern of taxation depends on the degree of centralization.

Consider first a fully centralized country. The ruler sets uniform taxes $\left(\tau_{l}, \tau_{m}\right)$ in all districts, where $\tau_{x}$ is the tax on activity $x=l, m$. Since market production yields greater surplus than local production, the optimal taxes $\left(\tau_{l}^{*}, \tau_{m}^{*}\right)$ seek to: (i) discourage local and home production and (ii) extract productive surplus. This is attained by setting:

$$
\tau_{l}^{*} \geq \frac{A_{l}-A_{h}}{A_{l}}, \tau_{m}^{*}=\frac{A_{m}-A_{h}}{A_{m}} .
$$

At these taxes, $n_{m}=1$ and the ruler extracts the full surplus $\left(A_{m}-A_{h}\right)$ from market production.

Consider the opposite benchmark of a fully decentralized country. The administration of each district $i$ is delegated to a local power holder (e.g. a nobleman) who sets taxes $\left(\tau_{l, i}, \tau_{m, i}\right)$ on local and market output. There are two differences with respect to centralization. First, market production initiated in district $i$ is now taxed also in the neighbouring district $i^{\prime}$ where it occurs: an agent operating in districts $i$ and $i^{\prime}$ pays a total tax rate of $\left(\tau_{m, i}+\tau_{m, i^{\prime}}\right)$, and his net income is $\left(1-\tau_{m, i}-\tau_{m, i^{\prime}}\right) A_{m}$. Local production is only taxed at home. Secondly, control over taxation allows each power holder to grab a share of tax revenues for himself. For simplicity, power holders keep all local tax revenues for themselves, but our results extend to milder assumptions.

Appendix A proves that in a symmetric equilibrium where each power holder $i$ noncooperatively sets optimal taxes $\left(\tau_{l, i}, \tau_{m, i}\right)$, we have:

Lemma 1. There always exist symmetric equilibria in which all districts set taxes $\tau_{l, d}=\left(A_{l}-\right.$ $\left.A_{h}\right) / A_{l}$ and $\tau_{m, d}>1-\left(A_{l}+A_{h}\right) / 2 A_{m}$. In these equilibria, everybody engages in local production.

8. As we will see later, the model assumes that production occurs at $t=1,2$ because at $t=1$ fiscal revenues are used to finance war, while at $t=2$ they are used for the ruler's consumption.

9. Our results go through if the ruler has some ability to borrow/lend in financial markets. A ruler's ability to borrow today increases in the fiscal revenues he can generate in the future. Thus, adding borrowing would fundamentally change our analysis (other than allowing rulers more flexibility to finance spending). 
This is a standard inefficiency from un-coordinated taxation-a common problem in early modern Europe (Epstein, 2002). Each local power holder tries to steal revenue from the others. As a result, taxes on market production are too high and market activity is too low. Tax revenues are also below the first best. ${ }^{10}$

We take the equilibria described in Lemma 1 as our decentralization benchmark: production in each district is $A_{l}$, each power holder obtains $A_{l}-A_{h}$, and the ruler's revenues are 0 . Despite the output gain generated by centralization, power holders prefer decentralization because they can keep tax revenues.

Consider now the intermediate case of a country where only a measure $\kappa \in(0,1]$ of districts are centralized. As the ruler internalizes social surplus across centralized districts, he sets taxes $\left(\tau_{l}^{*}, \tau_{m}^{*}\right)$ in all of them. The centralized region is equivalent to a fully centralized country consisting of $\kappa<1$ districts. ${ }^{11}$ In each centralized district, output is $A_{m}$ and the ruler's tax revenue is $\left(A_{m}-A_{h}\right)$. In each decentralized district, the local power holder overtaxes market production, setting the taxes $\left(\tau_{l, d}, \tau_{m, d}\right)$ of Lemma 1 , and grabs tax revenues.

As a result, when only $\kappa$ districts are centralized, total output and the central ruler's total tax revenue are, respectively, equal to:

$$
\begin{aligned}
& Y(\kappa)=A_{l} \cdot(1-\kappa)+A_{m} \cdot \kappa, \\
& R(\kappa)=\left(A_{m}-A_{h}\right) \cdot \kappa,
\end{aligned}
$$

and both increase in centralization $\kappa$. The ruler's revenue in equation (3.4) is equal to the surplus generated by market production times the measure of districts that are centralized. ${ }^{12}$

This setup captures the reality of early modern Europe where, before the formation of strong nation states, tax collection often relied on local representative bodies or noblemen. These operated through a system of regional monopolies and overlapping tax schemes which stifled factor mobility and innovation (Ertman, 1997). Centralizing and streamlining tax collection increased revenues for the monarch and allowed for less distortionary taxation, facilitating the growth of commerce. Of course, excessive political centralization might have well led to an undesirable concentration of power in early modern Europe. Consistent with this possibility, in Appendix B we show that in our model centralization of tax collection is most effective when it occurs in tandem with the creation of checks and balances limiting central power.

\subsection{State-building and domestic conflict}

At $t=0$ the ruler chooses what measure $\kappa$ of districts to centralize (initially, centralization is zero). To do so, he must overcome opposition by local power holders. These agents lose the tax

10. Indeed, the power holder of district $i$ faces a dilemma. He can either: (i) set a low tax on market production so as to encourage it or (ii) extract all surplus from local production. If adjacent power holders heavily tax market production, an atomistic power holder has no incentive to subsidize it. This game also admits an efficient equilibrium where all power holders coordinate on $\tau_{m, d}=\left(A_{m}-A_{h}\right) / 2 A_{h}$, so that market production occurs everywhere. We later discuss what happens if a measure $p$ of districts spontaneously coordinates on this efficient equilibrium.

11. Formally, the $\kappa$ centralized districts form a neighbourhood around the ruler's own district $i=1 / 2$. Market production occurs entirely within centralized districts. As the ruler obtains no revenue from decentralized districts, we assume that economic activity between centralized and decentralized districts is banned (there is a measure zero of such borders anyway). Thus, a partially centralized country can be split into a fully centralized and a fully decentralized region.

12. If a measure $p \in[0,1]$ of adjacent districts coordinate on the efficient equilibrium, total output becomes $Y(\kappa)=$ $A_{m}-(1-\kappa)(1-p)\left(A_{m}-A_{l}\right)$ while the ruler's revenue $R(\kappa)$ does not change with respect to equation (4). Coordination on the efficient equilibrium reduces the efficiency gains of centralization but leaves its impact on the ruler's fiscal revenue unchanged. 
rent $\left(A_{l}-A_{h}\right)$ under centralization, amounting to a loss of $2\left(A_{l}-A_{h}\right)$ over periods $t=1,2$. Local power holders cannot be compensated for the efficiency gains of centralization because at $t=0$ the ruler cannot commit to do so. In Section 5.2, we show how institutions can alleviate this commitment problem.

Overcoming opposition is costly: we assume that crushing or buying off the power holder of district $i$ costs the ruler $\beta_{i} \cdot 2 \cdot\left(A_{l}-A_{h}\right)$. Here $\beta_{i} \geq 0$ proxies for the ability and willingness of power holder $i$ to oppose the ruler, and is distributed across districts according to c.d.f $H(\beta) .{ }^{13}$ In countries with greater ethnic or religious divisions, or stronger regional power structures, $H(\beta)$ is lower in a "first-order stochastic dominance" sense. This reduced-form specification allows us to keep the analysis of external wars tractable. One key feature here is that power holders are atomistic. As we will see later, this precludes their coordination, which in turn implies that the cost of centralization stays unchanged during external wars. The regional interpretation of power holders is perhaps most intuitive, but we think of them as capturing all powerful domestic players capable of hindering the implementation of an administrative centralization programme.

The ruler begins to centralize districts with low conflict $\beta$ and then moves to more hostile districts. The cost of raising revenue $R$ in terms of centralizing $\kappa(R)=R /\left(A_{m}-A_{h}\right)$ districts is equal to:

$$
C(R)=2 \cdot\left(A_{l}-A_{h}\right) \cdot \int_{0}^{\beta(\kappa(R))} \beta \mathrm{d} H(\beta)
$$

where threshold $\beta(\kappa(R))$ defines the resistance faced by the ruler in the marginal district, which fulfils $H[\beta(\kappa(R))]=\kappa(R)$. We assume:

\section{Assumption 1. $\beta$ is uniformly distributed in $[0, B]$.}

This implies that equation (3.5) takes the convenient form:

$$
C(R)=B \cdot \frac{\left(A_{l}-A_{h}\right)}{\left(A_{m}-A_{h}\right)^{2}} \cdot R^{2} \equiv c \cdot R^{2},
$$

where $c \equiv B\left[\left(A_{l}-A_{h}\right) /\left(A_{m}-A_{h}\right)^{2}\right]$ pins down the marginal cost of reform. The cost of raising revenues is convex because marginal districts are increasingly opposed to reform. This cost grows with parameter $B$, which captures the strength of domestic conflict, and falls with the efficiency gains of market production, because a larger tax base makes it easier for the central ruler to raise additional revenues.

Consider the extent of centralization undertaken at $t=0$ in "autarky", namely absent any external threat. The ruler sets $R$ to maximize his utility over $t=0,1,2$. At $t=0$, the ruler's consumption utility is equal to domain income minus reform $\operatorname{cost} D-C(R)$. At $t=1$ and $t=2$, it is equal to the revenues generated in these periods. As a result, the ruler solves:

$$
\arg \max _{R} 2 R-c \cdot R^{2}
$$

13. Cost $2 \beta_{i} \cdot\left(A_{l}-A_{h}\right)$ can include both pecuniary and non-pecuniary components of a ruler's centralization effort (e.g. both the material resources as well as the organizational and emotional effort spent in conflict). This cost can be microfounded as a function of the fighting capabilities of the central ruler and of local powerholders. Results are available upon request. 
The ruler chooses $R$ by trading off the benefit of obtaining more fiscal revenues over $t=1,2$ with the cost of curtailing opposition at $t=0$. In autarky, the optimal tax revenue is then equal to:

$$
R_{\text {aut }}=\min \left[\frac{1}{B} \frac{\left(A_{m}-A_{h}\right)^{2}}{\left(A_{l}-A_{h}\right)},\left(A_{m}-A_{h}\right)\right],
$$

which is the product between the market production surplus $\left(A_{m}-A_{h}\right)$ in each district and the optimal degree of centralization $\kappa_{\text {aut }}$.

Fiscal revenues, and centralization, fall in the strength of domestic opposition $B$, which increases the cost of state-building, and increase in the relative productivity $A_{m} / A_{l}$ of market production, which increases the benefit of state-building. In our model, state formation is shaped by the tension between the advantages of a national market and the opposition against central rulers by local princes, cities, and estates. This rationalizes the notion that marketization and the "commercial revolution" contributed importantly to the rise of capable states in early modern Europe (Tilly, 1990; Karaman and Pamuk, 2010).

Throughout, we assume that $B>\left(A_{m}-A_{h}\right) /\left(A_{l}-A_{h}\right)$, which implies that fiscal revenues are below $\left(A_{m}-A_{h}\right)$; in other words, centralization in autarky is interior, $\kappa_{\text {aut }}<1$.

\section{WAR AND STATE-BUILDING}

There are two-countries, "home" $H$ and "foreign" $F$. At $t=1$ they enter armed conflict with probability $\theta$. If $\theta=0$, peace is guaranteed and each ruler makes decisions in autarky; if $\theta=1$, war occurs with certainty. Parameter $\theta$ captures war triggers unrelated to rulers' economic payoffs, such as empire-building motives, religious conflict, and inter-ruler rivalry. We assume that these events always trigger war. In Section 5.2, we allow rulers to choose whether or not to go to war conditional on the realization of a trigger.

War is costly. It absorbs the fiscal revenues of both rulers while it is fought, and redistributes fiscal revenues from the losing to the winning ruler thereafter. Denote by $R_{J}$ the fiscal revenues available at $t=1,2$ to the ruler of country $J=H, F$. If at $t=1$ there is a war, each ruler spends $R_{J}$ to wage it. ${ }^{14}$ At $t=2$, the winner is awarded the fiscal revenues of the two countries $R_{H}+R_{F}$. The loser obtains nothing. ${ }^{15}$ As a result, at $t=0$ the consumption utility of ruler $J$ is equal to $D-C_{J}\left(R_{J}\right)$, where $C_{J}\left(R_{J}\right)$ is the cost of his reform. If war does not break out, the ruler consumes $2 R_{J}$ over $t=1,2$. If instead war erupts, the ruler spends his $t=1$ revenues to wage the war, so that his consumption utility is zero in this period. At $t=2$, the war outcome is determined. The ruler consumes nothing if he loses, and he consumes $R_{H}+R_{F}$ if he wins.

The war outcome is stochastic and depends on the military strength of contestants. The military strength of country $J$ takes the Cobb-Douglas form $L_{J}^{\alpha} R_{J}^{\lambda}$, where $L_{J}$ is the size of the army. Parameters $\alpha, \lambda \geq 0$, respectively, measure the extent to which military might is driven by manpower and fiscal revenues. When $\lambda>0$, higher fiscal revenues render the army's "workforce" more productive by allowing a ruler to purchase better equipment, build more effective fortifications, and better train his soldiers. Holding $\alpha$ constant, a higher $\lambda$ captures

14. The assumption that at $t=1$ the ruler spends all fiscal revenues in the war is realistic. We studied the case in which at $t=1$ rulers choose how much to spend in the war and our main results continue to hold, particularly with the linear contest success function of Section 4.2. Results are available upon request.

15. This is a simplifying assumption. In reality, few states disappeared from the map altogether (cf. Section 2.3). In line with this argument, parameter $\theta$ can also be interpreted as the share of the losing ruler's revenue that the victorious ruler appropriates. 


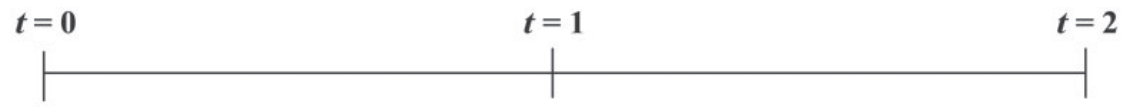

Rulers invest in fiscal $\quad \mathrm{Y}\left(R_{\mathrm{H}}\right), \mathrm{Y}\left(R_{\mathrm{F}}\right)$ is produced, $\quad \mathrm{Y}\left(R_{\mathrm{H}}\right), \mathrm{Y}\left(R_{\mathrm{F}}\right)$ is produced capacity $R_{\mathrm{H}}, R_{\mathrm{F}}$ revenues $R_{\mathrm{H}}$ and $R_{\mathrm{F}}$ are distributed to the rulers.

a) If there is no war, the ruler $\longrightarrow$ Each ruler consumes his consumes his revenue $R_{\mathrm{H}}$ or $R_{\mathrm{F}} . \quad$ revenue $R_{\mathrm{H}}$ or $R_{\mathrm{F}}$

b) If there is a war, the ruler uses his revenue $R_{\mathrm{H}}$ or $R_{\mathrm{F}}$ for $\longrightarrow$ The winning ruler consumes military expenses. $\quad R_{\mathrm{H}}+R_{\mathrm{F}}$, the losing ruler consumes nothing.

FIGURE 2

Timing

both a greater intensity of war in financial capital, as well as greater returns to scale in the military technology. We call parameter $\lambda$ the "money sensitivity of military strength", and view the military revolution as an increase in $\lambda$.

In line with much literature on conflict (see Dixit (1987) and Skaperdas (1992) for a review), we assume that ruler $H$ wins with probability:

$$
p\left(R_{H}, R_{F}\right)=\frac{L_{H}^{\alpha} R_{H}^{\lambda}}{L_{H}^{\alpha} R_{H}^{\lambda}+L_{F}^{\alpha} R_{F}^{\lambda}},
$$

while ruler $F$ wins with probability $1-p\left(R_{H}, R_{F}\right)$. Intuitively, the probability with which ruler $H$ wins the war increases with his military strength relative to ruler $F$. We take labor inputs as fixed, leaving for future work the endogenous determination of $\left(L_{H}, L_{F}\right)$. In Section 4.1, we focus on the simpler case in which $L_{H}=L_{F}$. We consider the case where $L_{H} \neq L_{F}$ in Section 4.2.

One key parameter here is the absolute value of the derivative of the contest function $\left|p_{J}\right|=$ $\left|\partial p\left(R_{H}, R_{F}\right) / \partial R_{J}\right|$. When $\left|p_{J}\right|$ is high, fiscal revenues are crucial to win the war. Equation (4.1) implies that:

$$
\left|p_{J}\right|=\lambda \cdot \frac{p(1-p)}{R_{J}},
$$

which increases, for given $\left(p, R_{J}\right)$, in the money sensitivity $\lambda$. In the theory of conflict, $\lambda$ is called "decisiveness parameter" and Hirshleifer (1995) associates its increase with a breakdown of anarchy.

Figure 2 summarizes the timing of the model. Given these preliminaries, ruler $H$ chooses revenue $R_{H}$ so as to solve:

$$
\max _{R_{H}} \theta \cdot\left\{p\left(R_{H}, R_{F}\right)\left(R_{H}+R_{F}\right)-2 R_{H}\right\}+2 R_{H}-c_{H} \cdot R_{H}^{2},
$$

while ruler $F$ chooses revenue $R_{F}$ so as to solve:

$$
\max _{R_{F}} \theta \cdot\left\{\left[1-p\left(R_{H}, R_{F}\right)\right]\left(R_{H}+R_{F}\right)-2 R_{F}\right\}+2 R_{F}-c_{F} \cdot R_{F}^{2} .
$$


Under risk neutrality, parameter $\theta$ can also be interpreted as the share of revenues (or land) a ruler can lose in the war. Because power holders are atomistic, their opposition to centralization does not vary with the probability of war $\theta$. As a result, the marginal cost $c_{J}$ of centralization is the same as in autarky and can differ across countries, owing to differences in domestic conflict $B_{J}$ among contestants. ${ }^{16}$ We henceforth refer to the marginal cost parameter $c_{J}$ as "domestic divisions" and to the country with lower cost as the "cohesive country". We abstract from differences in productive efficiencies, which are assumed to equal $A_{m}, A_{l}$ in all countries.

Equilibrium centralization levels constitute a Nash equilibrium of the game where rulers choose $R_{H}$ and $R_{F}$ according to (4.3) and (4.4). When the rulers' objective functions are concave (in the remainder we focus on parameter ranges where this is the case), a Nash equilibrium is identified by the first-order conditions:

$$
c_{H} \cdot R_{H}=1+(\theta / 2)\left[p_{H}\left(R_{H}+R_{F}\right)-(1-p)-1\right],
$$

for country $H$, and:

$$
c_{F} \cdot R_{F}=1+(\theta / 2)\left[-p_{F}\left(R_{H}+R_{F}\right)-p-1\right],
$$

for country $F$.

The presence of a war threat $(\theta>0)$ exerts three direct effects, which are included in square brackets above. First, war boosts the incentive to centralize: higher fiscal revenues enhance the probability of winning the war, allowing the ruler to predate on his competitor. This is the first term in square brackets (captured by $p_{H}>0$ and $p_{F}<0$ ). Secondly, war lowers the benefit of centralization by creating the risk that fiscal revenues are lost because of enemy conquest. By increasing its fiscal revenue, a ruler becomes a more attractive prey, which stunts his incentive to centralize. This is the second (negative) term in square brackets. Thirdly, and finally, the resource cost of war, which absorbs fiscal revenues at $t=1$, also reduces the benefit of centralization. This is the third (negative) term in square brackets.

Overall, war boosts a ruler's incentive to centralize when the sum of the terms in square brackets is positive while dampens it otherwise.

\subsection{Determinants of equilibrium state-building}

We now study what factors shape state-building in our model. Under the contest function in (4.1) the first-order conditions (4.5) and (4.6) are necessary and sufficient for an optimum provided the effect of fiscal resources on military strength is sufficiently low, $\lambda \gtrless 1$, so that the rulers' programme is concave. When $\lambda>1$ the rulers' maximization problem is no longer guaranteed to be concave, and the equilibrium may not exist or fail to be unique. This is why the literature on conflict has focused on $\lambda \leq 1$ (e.g. Hirshleifer, 1995). To shed light on the case $\lambda>1$, which is important for our analysis, in Section 4.2 we study the model under a linearized version of the contest success function in (9).

For now, consider the well behaved case $\lambda \leq 1$. Appendix A proves:

Proposition 1. When $\lambda \gtrless 1$ an equilibrium $\left(R_{H}^{*}, R_{F}^{*}\right)$ exists and is unique. When countries are symmetric, $c_{H}=c_{F}=c$, the equilibrium is also symmetric, and centralization is interior $\left(\kappa_{J}^{*}<1\right.$,

16. Allowing for non-atomistic power holders would complicate the analysis substantially. In particular, external conflict would unite power holders in favour or against the king depending on expected payoffs under the challenger. We leave analysis of these aspects to future research. 
$\forall J)$. In this symmetric equilibrium, we have that:

$$
R_{H}^{*}=R_{F}^{*}=\left(\frac{1}{c}\right)\left[1+\frac{\theta}{4}(\lambda-3)\right]
$$

so that the presence of a war threat reduces revenues and centralization relative to autarky. When countries are asymmetric, $c_{H} \neq c_{F}$, the unique equilibrium assigns higher revenue to the more cohesive country. The revenue of country $J$ : (i) drops in own domestic divisions $c_{J}$, and (ii) increases in domestic divisions abroad $c_{-J}$ if and only if country $J$ is the less cohesive one, namely $c_{J}>c_{-J}$.

The case of symmetric countries underscores the key role of the military technology. The higher is $\lambda$, the greater is the rulers' investment in state-building. When warfare becomes more reliant on making large technological and organizational investments, rulers have a stronger incentive to centralize to boost their revenues and predate on their competitor. Critically, though, when the level of money sensitivity is low, $\lambda<1$, the presence of a war threat stifles centralization relative to a peaceful world. Formally, centralization falls with the probability of war $\theta$. Intuitively, when $\lambda$ is low even the richest ruler becomes a prey with high probability, which reduces his incentive to centralize. This is the exact opposite of the conventional wisdom, according to which war necessarily fosters state-building (or leaves it unaffected).

Domestic divisions are also important. Consider property $(i)$ : the ruler facing less domestic conflict (i.e. lower cost $c_{J}$ ) is the more aggressive state builder and the more likely winner of war. Because power holders are atomistic, external conflict does not automatically transform state-building into a common interest public good. As a result, the ruler of a divided country may be unable to respond to external war as much as a cohesive opponent, creating divergence in state-building.

On the other hand, property (ii) highlights that when $\lambda \leq 1$ there are effects mitigating the extent of divergence in state-building: the ruler of the cohesive country centralizes less when his divided opponent centralizes more. This effect is due to a strategic interaction. As the divided ruler centralizes more, the cohesive ruler faces a higher risk of losing the war, which in turn reduces his incentive to centralize. This effect critically relies on having a low money sensitivity: the risk of losing to a poorer opponent is sufficiently high only when $\lambda$ is low. Formally, when $\lambda \leq 1$ the reaction function of the cohesive country is negatively sloped, while that of the divided country is positively sloped. Hence, if the reaction function of the divided country shifts up, state-building in the cohesive country drops. Figure 3 shows this effect when $F$ is the cohesive ruler (i.e. $\left.c_{F}<c_{H}\right)$.

What happens when money sensitivity is high? As discussed above, we cannot characterize the equilibria for $\lambda>1$ under the non-linear contest function in equation (9). Yet, even in this case, the above analysis allows us to make two useful remarks (these are proved in the Proof of Proposition 1).

First, consider the case in which countries are symmetric $\left(\right.$ i.e. $\left.c_{H}=c_{L}\right)$. Then, if a symmetric equilibrium exists, its revenues are pinned down by in equation (16). In this case, then, a higher probability of war $\theta$ increases state-building for $\lambda>3$. When money sensitivity is high, external war causes state-building to go up, in line with conventional wisdom.

Secondly, consider the case in which countries are asymmetric (i.e. $c_{H} \neq c_{L}$ ). Then, if an interior equilibrium exists, stronger centralization by the divided ruler increases the incentive of the cohesive ruler to centralize. When money sensitivity is high, the cohesive ruler is very keen in centralizing to conquer a better prey. As a result, external war causes strong divergence in state-building. 


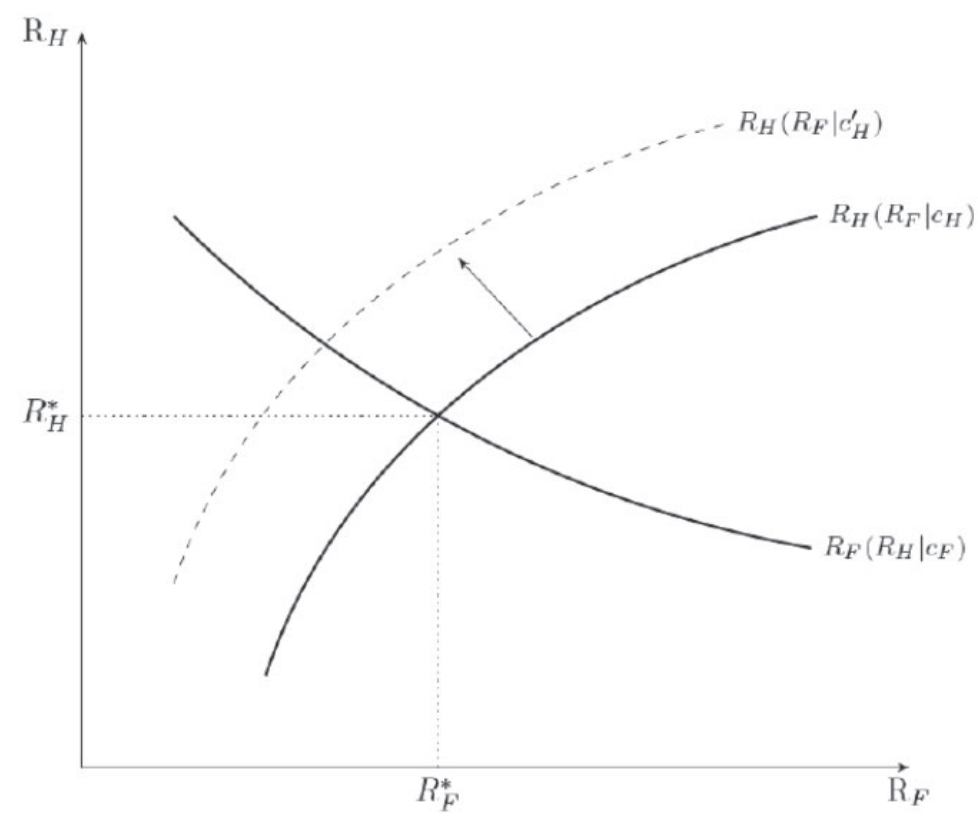

FIGURE 3

Revenue-raising and military success

In sum, the military technology is critical in determining the effect of external wars on statebuilding across countries. When the money sensitivity of war is low (i.e. $\lambda \leq 1)$, military conflict causes a race to the bottom reducing state-building in all countries, and strategic interactions among reforms dampen inequality in state-building across countries. When money sensitivity is high, military conflict causes a race to the top, so that-if an interior equilibrium exists-the properties of Proposition 1 are twisted. Rulers of cohesive countries have a strong incentive to centralize, and rulers of divided countries "give up", reducing their state-building as their competitors grow stronger. To study globally the equilibrium for $\lambda>1$, and to analyse in detail the interaction between military technology $\lambda$ and inequality in domestic divisions $c_{H} / c_{F}$, we turn to a linearized version of our model.

\subsection{Linearized contest success function}

We linearize (4.1) around the point where both countries win with probability $1 / 2$, and obtain: ${ }^{17}$

$$
p\left(R_{H}, R_{F}\right)=\frac{1}{2}+\lambda \cdot\left(R_{H}-\gamma \cdot R_{F}\right) .
$$

The money sensitivity of military strength $\lambda$ pins down the slope of the win probability with respect to fiscal revenues. The relative army size $L_{F} / L_{H}$ shapes the relative effectiveness of revenues in country $F$, because $\gamma \equiv\left(L_{F} / L_{H}\right)^{\alpha / \lambda}$. This is due to money labour complementarity.

17. Formally, equation (4.1) is linearized around the symmetric revenues $\left(R_{H, 0}, R_{F, 0}\right)$ such that $L_{H}^{\alpha} R_{H, 0}^{\lambda}=L_{F}^{\alpha} R_{F, 0}^{\lambda}$. We normalize $R_{H, 0}$ to 1 , which allows us to get rid of a multiplicative constant in our expressions, without affecting our main results. 
More broadly, $\gamma \neq 1$ can be accounted for by any factor making a country's military spending more productive.

We first consider in Proposition 2 the simplest case $\gamma=1$ in which the two countries are equally effective at war. One shortcoming is that when $\gamma=1$ the contest success function in equation (4.8) does not allow for the strategic interactions discussed in property $i i)$ of Proposition 1. Corollary 1 studies the role of these strategic interactions by considering the case in which $\gamma \neq 1$ (owing to different army sizes or productivities).

In Appendix A, we prove the following result:

Proposition 2. (case $\gamma=1$ ) Suppose that $\lambda \gtrless \max \left(c_{H}, c_{F}\right) / \theta$, so that the rulers' problem is concave. Then:

(1) If $c_{H}=c_{F}=c$, a symmetric equilibrium exists and is unique. Rulers' revenues: ( $i$ ) increase in money intensity $\lambda$, and (ii) increases in the war threat $\theta$ if and only if $\lambda>(3 / 4) c$.

(2) If $c_{H} \neq c_{F}$, there is a $z>1$ such that, for $\frac{\max _{J} c_{J}}{\min _{J} c_{J}}<z$, an asymmetric equilibrium exists and is unique. In such equilibrium, $R_{H}^{*}>R_{F}^{*}$ if and only if $c_{H}<c_{F}$. The equilibrium revenue of both rulers (weakly) increases in $\lambda$. In addition: ( $i)$ the revenues of ruler $J$ increase in the war threat $\theta$ if and only if $\lambda>(3 / 4) c_{J}$, and (ii) if centralization is interior $\left(\kappa_{J}<1, \forall J\right)$, higher $\theta$ increases inequality among countries, in the sense that $R_{H}^{*} / R_{F}^{*}>R_{H, \text { aut }} / R_{F}$,aut if and only if $c_{H}<c_{F}$.

As long as money sensitivity is sufficiently low so that the ruler's maximization problem is concave, the equilibrium has a simple characterization. In the symmetric case, centralization increases with the importance of money for military success $\lambda$. Critically, if $\lambda$ is sufficiently large relative to domestic divisions $c_{J}$, the presence of a war threat now boosts state-building, in line with conventional wisdom. In other words, when fiscal revenues buy military success, rulers have a strong incentive to centralize to prey on their opponents.

Point (2) highlights an interesting interaction between external war and domestic divisions. Because divided countries find it uniformly harder to centralize, war threats increase inequality in state-building. This is due to the effect-discussed in Proposition 1-that the ruler of the internally divided country finds it hard to build a strong state. As a result, he perceives a strong risk of becoming a prey, which stunts his incentive to centralize. ${ }^{18}$

To see these effects, suppose that centralization is interior. In this case, the equilibrium revenue of ruler $J$ is equal to:

$$
R_{J}^{*}=\left(\frac{1-3 \theta / 4}{1-\lambda \theta R_{J, a u t}}\right) \cdot R_{J, a u t} .
$$

Where $R_{J, a u t}=1 / c_{J}$ is the autarky revenue in country $J$. Suppose that country $H$ is less divided than country $F$, formally $B_{H}<B_{F}$, which implies $c_{H}<c_{F}$. Then, denoting by $R_{\text {aut }}$ the autarky revenue in $H$, the autarky revenue in $F$ is $R_{F, a u t}=\left(B_{H} / B_{F}\right) R_{\text {aut }}$.

Figure 4 plots the pattern of equilibrium state-building in the two countries. Along the horizontal axis, a higher $R_{\text {aut }}$ reflects a global boost in the efficiency of market production,

18. In Proposition 2, the upper bound $z$ in inequality ensures that both countries have a positive probability to win. This restriction is realistic: in our sample no country wins all its battles. Even highly successful military powers such as Britain, Prussia, and Russia have a fair share of defeats - chance continues to play an important role right to the end of our period (and beyond, as reflected in Napoleon's famous dictum that luck was the single-most important attribute of a general). Additionally, as we show in the Appendix, interior win probabilities are necessary to ensure existence of asymmetric equilibria under the linear function in equation (16). 


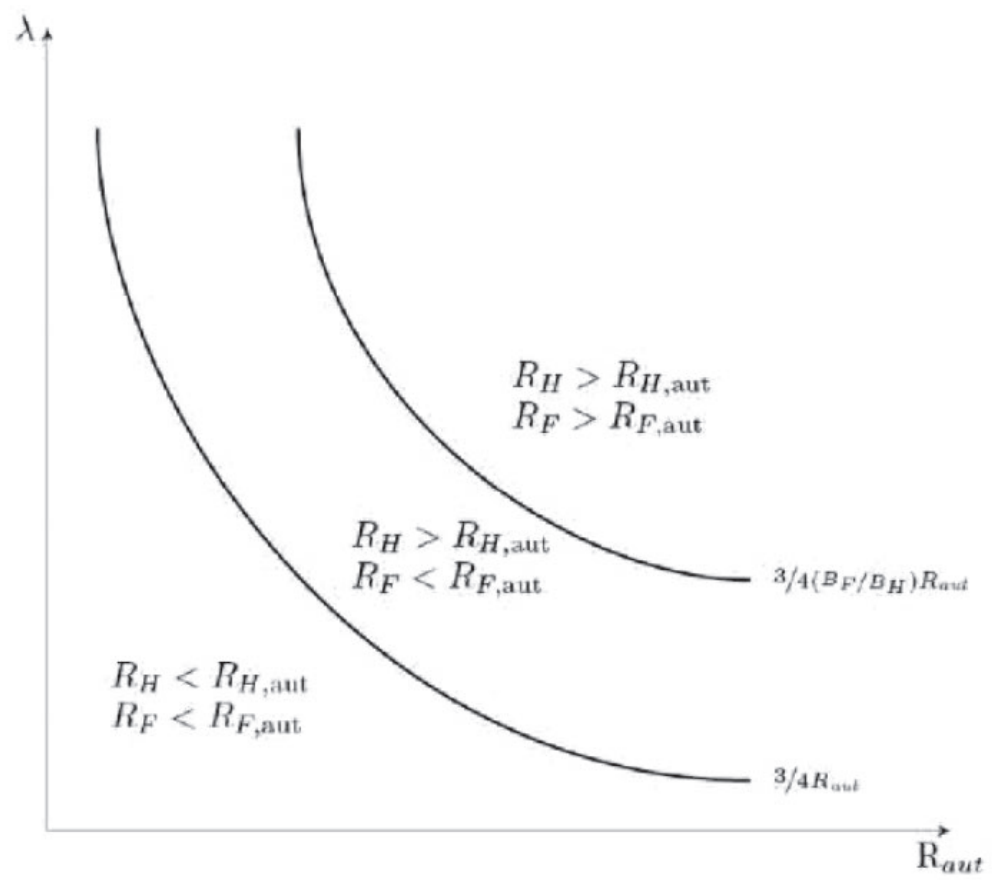

FIGURE 4

Revenue raising and the military value of fiscal revenue

Notes: The $y$-axis shows the country-specific sensitivity of revenue-raising to $\lambda$, the value of money in winning wars. The $x$-axis measures revenue in autarchy.

due to increasing commercialization, which reduces the marginal cost of creating fiscal revenues in all countries. The vertical axis reports $\lambda$.

Three patterns of state-building can occur as a function of $\lambda$. When the sensitivity of war to fiscal revenues is low relative to the cost of centralization $\left(\lambda \leq 3 \cdot c_{H} / 4\right)$, the risk of losing fiscal revenues in a war is large even for the richer power. As a result, external war causes a race to the bottom that discourages state-building in all countries. This is is the southwest region of Figure 4. The state system is fragmented, the balance of power within political entities is unstable, and it does not lead to the emergence of a strong power.

As the influence of money on military success increases, rulers become more hungry for fiscal revenues. They increasingly centralize and streamline tax administration. As a result, taxes become less distortionary, which spurs commerce and growth and makes the prospect of conquering the opponent more attractive, begetting further state-building.

At some point, money sensitivity reaches the intermediate region $\left(3 \cdot c_{H} / 4<\lambda<3 \cdot c_{F} / 4\right)$. In this case, the richer power is significantly less likely to fall prey to its opponent. As a result, external war creates strong inequality: the rulers of less divided countries disproportionately centralize while those of less powerful countries still restrain their statebuilding efforts relative to autarky. Now the international system consists of politically strong and economically developed centralized countries and weaker, poorer, less centralized countries. These laggard countries are unlikely to survive as they increasingly fall prey to the strong ones. 
Finally, as $\lambda$ becomes very high $\left(\lambda \geq 3 \cdot c_{F} / 4\right)$, we enter a third phase where all rulers boost their state-building efforts. This is the northeast region of Figure 4. Here, rulers converge to the full centralization benchmark where tax distortions are lowest and production is highest.

Consider now the case $\gamma \neq 1$. We focus on the case in which country $H$ is more effective at war-making than $F$, namely $\gamma \leq 1$. The result below then shows that in this case divergence can be very pronounced:

Corollary 1. $(\gamma \leq 1)$. Suppose that $\lambda \leq \max \left(c_{H}, c_{F}\right) / \theta$, so that the rulers' problem is concave. Then, if country $H$ is more cohesive than $F$ (i.e. $c_{F}>c_{H}$ ), war threats increase divergence, in the sense that for any $\theta>0, R_{H} / R_{F}$ is larger than in autarky and increases in $\lambda$. Furthermore, there exists a threshold $\widehat{\gamma}<1$ such that for all $\gamma<\widehat{\gamma}$ higher money sensitivity $\lambda$ increases the equilibrium revenue of the cohesive country $H$ while it decreases the revenue of the divided country $F$.

If country $F$ is both more domestically divided and weaker in the battlefield than country $H$ (i.e. $c_{F}>c_{H}$ and $\gamma<1$ ), divergence in state-building is very strong. The strategic interaction among reforms discussed in Point (ii) of Proposition 1 play a key role here. As money sensitivity $\lambda$ increases, the cohesive country centralizes a lot to prey upon its weaker opponent. Unable to withstand the competition, the divided country gives up, actually reducing its state-building.

In sum, military competition can cause significant departures from the conventional portrayal of war as a common interest public good that induces accelerated investments in state capacity. On the one hand, as documented in Propositions 1 and 2, higher frequency of conflict may reduce state-building in all countries when money sensitivity $\lambda$ is low. On the other hand, as shown by Corollary 1 , high levels of money sensitivity $\lambda$ increase state-building in the country that is cohesive and most effective at war but reduce state-building in weaker opponents, fostering divergence.

\section{INSTITUTIONS, STATE BUILDING, AND THE DECISION FOR WAR}

We now show that the link between state-building and the military technology becomes stronger once one accounts for the possibility for rulers to create institutional constraints limiting their own prerogatives, as well as for their endogenous choice of whether or not to go to war.

\subsection{Institutions and state-building}

We view institutions as constraints limiting the ability of the central ruler to extract resources from power holders under centralization (Acemoglu et al., 2001). Institutions set the share $\left(1-\pi_{J}\right) \in$ $[0,1]$ of tax revenues that the ruler can extract from a centralized district in country $J=H, F$. The remaining share $\pi_{J}$ of taxes goes to the power holder. As before, power holders fully retain fiscal revenues in decentralized districts. When $\pi_{J}=0$, the central ruler is unconstrained, as in previous analysis. Higher $\pi_{J}$ captures greater power of legislative assemblies, constitutional review, and so forth. ${ }^{19}$

Consider the payoff implications of introducing institutions. Given an amount of fiscal revenues $R_{J}=\kappa_{J} \cdot\left(A_{m}-A_{h}\right)$ collected in centralized districts, the total revenue accruing to the

19. This arrangement might be seen as giving to a local elite assembly control over a share $\pi_{J}$ of revenues. We solved the model under the alternative assumption that institutions create a representative assembly of power holders that votes on whether to give fiscal revenues to the central ruler or not. Our main analysis focus on a more tractable model without this state-contingent mechanism. 
central ruler is now equal to $\widetilde{R}_{J}=\left(1-\pi_{J}\right) \cdot R_{J}$. The power holder of a centralized district now obtains $2 \pi_{J} \cdot\left(A_{m}-A_{h}\right)$ over two periods (which is equal to zero in the absence of institutions). As a result, when a district is centralized, the loss experienced by its power holder is equal to $2\left[\left(A_{l}-A_{h}\right)-\pi_{J} \cdot\left(A_{m}-A_{h}\right)\right]$, and falls in the strength of institutions. Indeed, institutions allow power holders to internalize some of the efficiency gains of centralization. If the institutional commitment to share these gains is sufficiently strong, namely

$$
\pi_{J} \geq \widehat{\pi}_{J} \equiv \frac{\left(A_{l}-A_{h}\right)}{\left(A_{m}-A_{h}\right)},
$$

then even local power holders gain from centralization. In this extreme case, institutions enable a mutually advantageous revenue-sharing arrangement, and there is no local opposition to statebuilding.

In reality, of course, it is hard for the ruler to create institutions that are so strong. To capture this idea, we assume that the ruler must bear an increasing and convex cost $K\left(\pi_{J}\right)$ to create institutions (implicitly, there are no institutional safeguards at the outset, $\pi_{0, J}=0$ ). Provided the cost of institution-building is large enough — which we assume throughout - the ruler will set $\pi_{J}<\widehat{\pi}_{J}$.

Taking this into account, at the outset each ruler optimally chooses $\pi_{J}$; next, he sets centralization $\kappa_{J}$; finally, military and market interactions occur. By solving the model backwards, Appendix B shows that in autarky, after having optimally set institutions, the ruler's revenue is equal to:

$$
\widetilde{R}_{J, a u t}=\left(1-\pi_{J, a u t}\right) \cdot \min \left[\frac{\left(1-\pi_{J, a u t}\right)\left(A_{m}-A_{h}\right)^{2}}{B_{J}\left[\left(A_{l}-A_{h}\right)-\pi_{J, a u t} \cdot\left(A_{m}-A_{h}\right)\right]},\left(A_{m}-A_{h}\right)\right],
$$

where $\pi_{J, \text { aut }}$ is the strength of institutions set by the ruler in autarky.

Equation (B.2) shows that stronger institutions exert two conflicting effects on $\widetilde{R}_{J, \text { aut }}$ (i.e. on the inverse of the cost of centralization). On the one hand, higher $\pi_{J}$,aut reduces power holders' opposition to centralization. This increases centralization and fiscal revenues. On the other hand, higher $\pi_{J \text {,aut }}$ reduces the share of fiscal revenues appropriated by the ruler. This reduces the ruler's revenues. The case to consider is the one in which the first effect dominates, so that fiscal revenues increase in $\pi_{J}$. Indeed, rulers will never set institutions in the decreasing range. In this range, Appendix B shows that stronger institutions can be conceptualized as a reduction in the marginal cost $\tilde{c}_{J}$ of raising fiscal revenues.

The mapping between institutions and the cost of centralization suggest an important observation: for given domestic divisions $B_{J}$, the country having better institutions centralizes relatively more than its opponent, enjoying greater fiscal revenues. In line with this prediction, Dincecco (2009) documents that constrained governments in Europe taxed more than fragmented or "absolutist" entities between 1650 and 1913.

Furthermore, Appendix B shows that in our model (as in Besley and Persson 2009), different dimensions of state development-centralization and institutional quality-cluster together. In a cohesive country, the ruler chooses to invest in institutional upgrading, particularly when he must centralize to meet an external war threat. In a divided country, only major institutional improvements can reduce opposition to centralization. This discourages the ruler from undertaking both institutional upgrading and state-building, stifling all reforms.

Critically, the strength of these effects is shaped by the military technology. When $\lambda$ is low, the external war threat dampens investments in institutions and centralization in all countries. As $\lambda$ becomes intermediate, only the ruler of the less divided country boosts centralization and 
institutional quality, generating strong divergence. A very large $\lambda$ leads to the emergence of strong and accountable states everywhere.

\subsection{State building and the decision for war}

We now show that the link between state-building and the military technology becomes stronger once we endogenize the decision to go to war. Suppose that a war trigger arises (with probability $\theta$ ). Both rulers have financed their armies, they are ready to go to war, but can choose whether or not to fight. If war is averted, each ruler enjoys his future revenues with probability one. If war occurs, the usual war lottery is played. Critically, war destroys a share $(1-\sigma)>0$ of revenues at $t=2$ in all countries. Given this deadweight loss, it would be welfare improving to avoid war through negotiations, but we realistically assume that such negotiations do not occur because rulers cannot commit to making the necessary transfers. This implies that war does not occur if both rulers lose from war, but it occurs when either ruler expects to benefit from it (given $\sigma<1$, it is impossible for both rulers to gain from war). ${ }^{20}$

We now solve the model under these assumptions. This amounts to characterizing the rulers' decision of whether or not to go to war for given equilibrium revenues $\left(R_{H}^{*}, R_{F}^{*}\right)$, and then to endogenously solve for these revenues at the ex ante stage, when the probability $\theta$ of the war trigger and the choice to go to war are all taken into account.

To solve the model backwards, consider the last stage. Given equilibrium revenues $\left(R_{H}^{*}, R_{F}^{*}\right)$, and conditional on the realization of a war event, conflict occurs either when $H$ benefits from triggering a war, formally when:

$$
p\left(R_{H}^{*}, R_{F}^{*}\right) \cdot \sigma \cdot\left(R_{H}^{*}+R_{F}^{*}\right) \geq R_{H}^{*},
$$

or when $F$ benefits from triggering a war, namely when:

$$
\left[1-p\left(R_{H}^{*}, R_{F}^{*}\right)\right] \cdot \sigma \cdot\left(R_{H}^{*}+R_{F}^{*}\right) \geq R_{F}^{*} .
$$

War is averted if and only if none of the above conditions holds. Intuitively, equations (5.3) and (5.4) ensure that a ruler's payoff from going to war-the left-hand side in the above expressionsis higher than what he can obtain by taxing only his own economy-the right-hand side above.

Under the assumed symmetric contest success function [i.e. given that $p(R, R)=1 / 2$ ], it is easy to show that war cannot occur in a symmetric equilibrium where countries raise the same revenue $\left(R_{H}=R_{F}\right)$; in this case, going to war is like burning some fiscal revenues to toss a coin. Given risk neutrality, no ruler is willing to do it. Hence, when $R_{H}=R_{F}$ both rulers prefer peace.

The incentive to go to war arises instead if countries are unequal, namely $R_{H} \neq R_{F}$. In this case, the war favours one contestant, who may be eager to initiate conflict. In solving for a full equilibrium, Appendix A shows that under the linear contest function, and under the assumptions of Point (2-ii) of Proposition 2 we find:

Proposition 3. Let $\lambda^{*}$ be defined as the threshold such that for $\lambda \leq \lambda^{*}$ centralization in the two countries is partial, namely $\kappa_{J}^{*}<1$ for $J=H, F$. Then, there are two thresholds $\lambda_{0}, \lambda_{1}$ where

20. Jackson and Morelli (2007) discuss a different commitment problem, one in which there is full commitment to transfers (which in their setting occur in the present), but no commitment to future peace. In such a setting, the authors show that under some conditions it is possible to find a current transfer that renders future peace sustainable. In our model, contestants cannot make transfers in the current period because countries have already invested their current revenues to building an army. As a result, avoiding war requires countries to commit to making future transfers after peace has been established. 
$0 \leq \lambda_{0}<\lambda_{1} \leq \lambda^{*}$ such that, conditional on the realization of a war event:

(1) If $\lambda \leq \lambda_{0}$, war occurs with probability one and the more divided (poorer) ruler expects to benefit from it.

(2) If $\lambda \in\left(\lambda_{0}, \lambda_{1}\right)$, the equilibrium is in mixed strategies and war occurs with an equilibrium probability $\omega \in[0,1)$.

(3) If $\lambda \geq \lambda_{1}$, war occurs with probability one and the more cohesive (richer) ruler stands to benefit from it.

War is most likely to arise if financial resources influence military success either to a great extent, or hardly at all. Crucially, the identity of the party initiating conflict differs in these two cases. When the influence of financial resources on military success is high, the rich country is the one initiating conflict. Because this country is disproportionately more likely to win, it is eager to attack. When instead the money sensitivity of the war outcome is low, the less wealthy country is the one initiating conflict. This country wins the war with less than $50 \%$ probability. However, because of the low $\lambda$, the odds for such a country to win are non-negligible, and the payoff of conquering a wealthy opponent acts as an inducement to conflict. ${ }^{21}$ The role of war technology in shaping whether the poor or rich country attacks is also discussed in Jackson and Morelli (2007).

There are two important implications. First, the link between the war technology and the frequency of military conflict is non-linear. As a result, it is difficult to draw univocal predictions linking the frequency of conflict, the war technology and state-building. Secondly, and more interestingly, endogenous wars create an additional force towards convergence or divergence. When $\lambda$ is low, state consolidation is weak not only because each ruler has little incentive to centralize, but also because war redistributes revenues from larger countries to smaller ones, fostering fragmentation. In contrast, when $\lambda$ is high, state consolidation is extensive not only because each ruler has strong incentives to centralize, but also because war redistributes fiscal revenues and territories from smaller countries to larger ones, increasing concentration.

\section{EMPIRICAL RESULTS}

We now confront the main predictions of our model with data from early modern Europe. We first examine how much money mattered for victory on the battlefield. Next, we take the estimated money sensitivity of war and study its interaction with domestic divisions in shaping statebuilding. In particular, we test whether increasing money sensitivity and domestic divisions can explain the occurrence of declines in fiscal capacity. The goal of our analysis is not to identify the causal impact of changing war technology and domestic divisions on state-building, but to assess whether the basic correlations in the data are consistent with our theory. ${ }^{22}$

\subsection{Financial Resources and Military Success}

To demonstrate the growing importance of financial resources for military success, we analyse 374 battles in Europe between 1500 and 1800 - the period when state consolidation accelerated. For each battle, we code the outcome as either success or defeat. ${ }^{23}$

21. When $\lambda$ is intermediate, the probability of war $\omega \in(0,1)$ is determined so that - at the optimal investments in state-building - the more belligerent ruler is just indifferent between initiating war or not. See Appendix A for details.

22. Data and STATA do-files for replication are available as supplementary material on the RESTUD website.

23. We combine information in Jaques (2007) on battles with data from Landers (2003) on the outcomes of conflicts. We also use fiscal data from the European State Finance Database (ESFD); Bonney 1989), as compiled, augmented and 


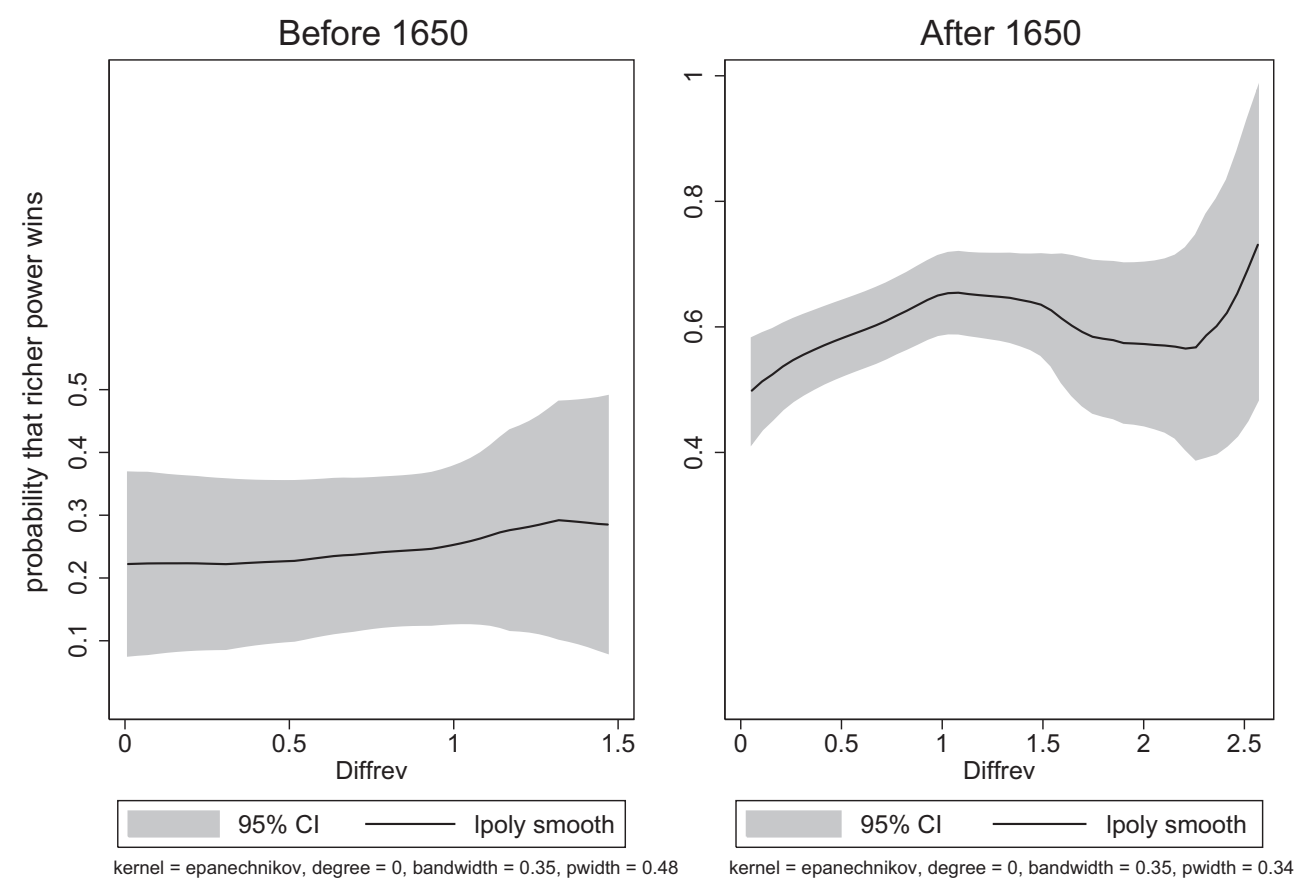

FIGURE 5

War and fiscal resources

Notes: The graph shows the smoothed local polynomial and $95 \%$ confidence intervals. The $y$-axis measures the probability of the richer power winning in battle. Note that battle outcomes are coded as either victory or draw, meaning that the probability of the poorer power winning is not equal to 1-probability of richer power winning. The $x$-axis shows the $\log$ difference in total fiscal revenue, calculated as Diffrev $=\ln \left(T_{H, t}\right)-\ln \left(T_{L, t}\right)$, where $T_{H, t}$ is the tax revenue of the fiscally stronger power, $T_{L, t}$ is the revenue of the fiscally weaker power.

Figure 5 presents a simple way of looking at the extent to which money spelled military might. We plot the local polynomial of the probability of success as a function of the (log) revenue difference between combatant states. During the period 1500-1650, richer powers enjoyed no discernable benefit - on average, they won less than $50 \%$ of the time, and a greater revenue advantage did not translate into more frequent battlefield success. After 1650, however, richer powers consistently won more often than their opponents. As the right panel in Figure 5 shows, the greater the revenue advantage, the higher the chances of success. In the second period, the richer power's probability of victory was up to three times higher than that of a poorer belligerent.

To obtain a parametric estimate of money sensitivity, we run the following regression for the likelihood of success for the richer power:

$$
S_{H, t}=C+\lambda_{1}\left[\ln \left(T P_{t}^{H}\right)-\ln \left(T P_{t}^{L}\right)\right]+\lambda_{2}\left[\ln \left(p_{t}^{H}\right)-\ln \left(p_{t}^{H}\right)\right]+\beta X^{\prime}+\alpha_{\epsilon_{H, t}}
$$

where $S_{H, t}$ is a dummy variable equal to unity if the stronger power wins, and zero otherwise, $C$ is a constant, and $T_{H, t}\left(P_{H, t}\right)$ is the tax revenue (population) of the fiscally stronger power, $T_{L, t}$

summarized by Karaman and Pamuk (2010). For each combatant state, we collect data on total tax revenue at the nearest point in time, as well as on population size (from McEvedy and Jones, 1978). Variable construction is described in detail in Appendix E. 
TABLE 3

Battlefield success and fiscal revenues (dependent variable: BattleOutcome)

\begin{tabular}{|c|c|c|c|c|c|c|}
\hline & (1) & (2) & (3) & $\begin{array}{c}(4) \\
\text { timeFE }\end{array}$ & $\begin{array}{c}(5) \\
\text { Pre-1650 }\end{array}$ & $\begin{array}{c}(6) \\
\text { Post-1650 }\end{array}$ \\
\hline Diffrev & $\begin{array}{c}0.43 * \\
(1.65)\end{array}$ & $\begin{array}{l}0.43 * \\
(1.65)\end{array}$ & $\begin{array}{c}0.43 * \\
(1.65)\end{array}$ & $\begin{array}{l}0.58 * * \\
(2.07)\end{array}$ & $\begin{array}{c}0.45 \\
(1.14)\end{array}$ & $\begin{array}{c}0.62 * \\
(1.87)\end{array}$ \\
\hline Diffpop & $\begin{array}{l}0.025 \\
(0.20)\end{array}$ & $\begin{array}{l}0.027 \\
(0.20)\end{array}$ & $\begin{array}{l}-0.0041 \\
(-0.03)\end{array}$ & $\begin{array}{l}-0.13 \\
(-0.98)\end{array}$ & $\begin{array}{l}0.13 \\
(0.61)\end{array}$ & $\begin{array}{l}-0.18 \\
(-1.13)\end{array}$ \\
\hline Allies & & $\begin{array}{c}0.14 \\
(1.23)\end{array}$ & $\begin{array}{c}0.069 \\
(0.48)\end{array}$ & $\begin{array}{c}0.20 \\
(1.00)\end{array}$ & $\begin{array}{c}0.035 \\
(0.10)\end{array}$ & $\begin{array}{c}0.26 \\
(1.18)\end{array}$ \\
\hline Naval & & & $\begin{array}{l}-0.24 \\
(-0.78)\end{array}$ & $\begin{array}{l}-0.38 \\
(-1.46)\end{array}$ & $\begin{array}{c}-0.64 \\
(-1.36)\end{array}$ & $\begin{array}{l}-0.38 \\
(-1.31)\end{array}$ \\
\hline Constant & $\begin{array}{c}-0.24 \\
(-0.83)\end{array}$ & $\begin{array}{l}-0.29 \\
(-0.94)\end{array}$ & $\begin{array}{c}-0.18 \\
(-0.46)\end{array}$ & $\begin{array}{l}-1.41 * * * \\
(-5.24)\end{array}$ & $\begin{array}{l}-1.45 * * * \\
(-11.38)\end{array}$ & $\begin{array}{c}0.23 \\
(0.75)\end{array}$ \\
\hline$N$ & 257 & 257 & 257 & 253 & 38 & 215 \\
\hline
\end{tabular}

Notes: $* p<0.1, * * p<0.05$, *** $p<0.01$; standard errors clustered at the opponent-pair level, in parentheses; Diffrev is the log difference of fiscal revenue between the richer and the poorer power; Diffpop is the log difference in population; Allies is a dummy for battles fought with allies, and Naval take the value of unity for engagements at sea. See Appendix E for sources.

$\left(P_{L, t}\right)$ is the revenue (population) of the fiscally weaker power, and $X^{\prime}$ is a vector of controls. We focus on the relative difference in fiscal strength by calculating log differences. The estimated coefficient $\widehat{\lambda_{1}}$ captures the importance of money for winning a war, providing a proxy for the sensitivity of battlefield success to fiscal revenues $\lambda$ in our model.

Table 3 presents the results of estimating probit models. ${ }^{24}$ Independent of the specification used, we find a significant effect of larger revenue differences on battlefield success. Col 1 suggests that, evaluated at the sample mean, a one standard deviation increase in the log revenue ratio increases the odds of success from 0.545 to 0.628 - a gain of 8.3 percentage points. Differences in population size do not have a systematic effect on the chances of battlefield success. This finding is robust to controls for the presence of allies and naval battles. Controlling for time fixed-effects does not overturn our results. Critically, and consistent with the role of the military revolution, the estimated money sensitivity $\lambda$ increases substantially during our sample period. Before 1650, the link between battlefield success and fiscal resources is positive, but relatively small and imprecisely estimated (column 5). After 1650, the effect becomes almost 50\% larger, and it is highly significant (column 6). We therefore conclude that after 1650, fiscal revenue became a much better predictor of battlefield success.

\subsection{Determinants of fiscal capacity}

Our model predicts that a state's ability to raise taxes falls with pre-existing domestic conflicts and divisions. Critically, relative to existing theories (e.g. Besley and Persson 2009), our model makes the further prediction that domestic divisions should only generate strong divergence in state-building as money becomes important for military success. In particular, when this occurs, weaker powers should "give up", abandoning serious attempts to engage in state-building. We now look at the data considering these predictions one at the time.

24. Standard errors are clustered at the opponent-pair-period level, so that two battles between the same adversaries in the same 50-year period (with identical values for revenue) receive less weight than two battles between different powers in different periods. Table A3.1 in Appendix C shows that results are largely unchanged if we restrict the sample to battles without allies. 


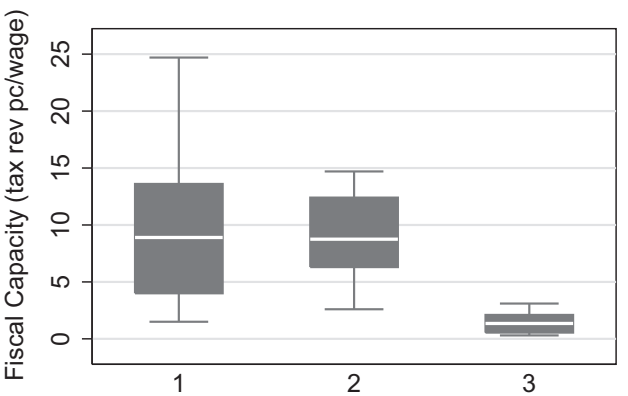

Terciles, no. of predecessor states in 1300
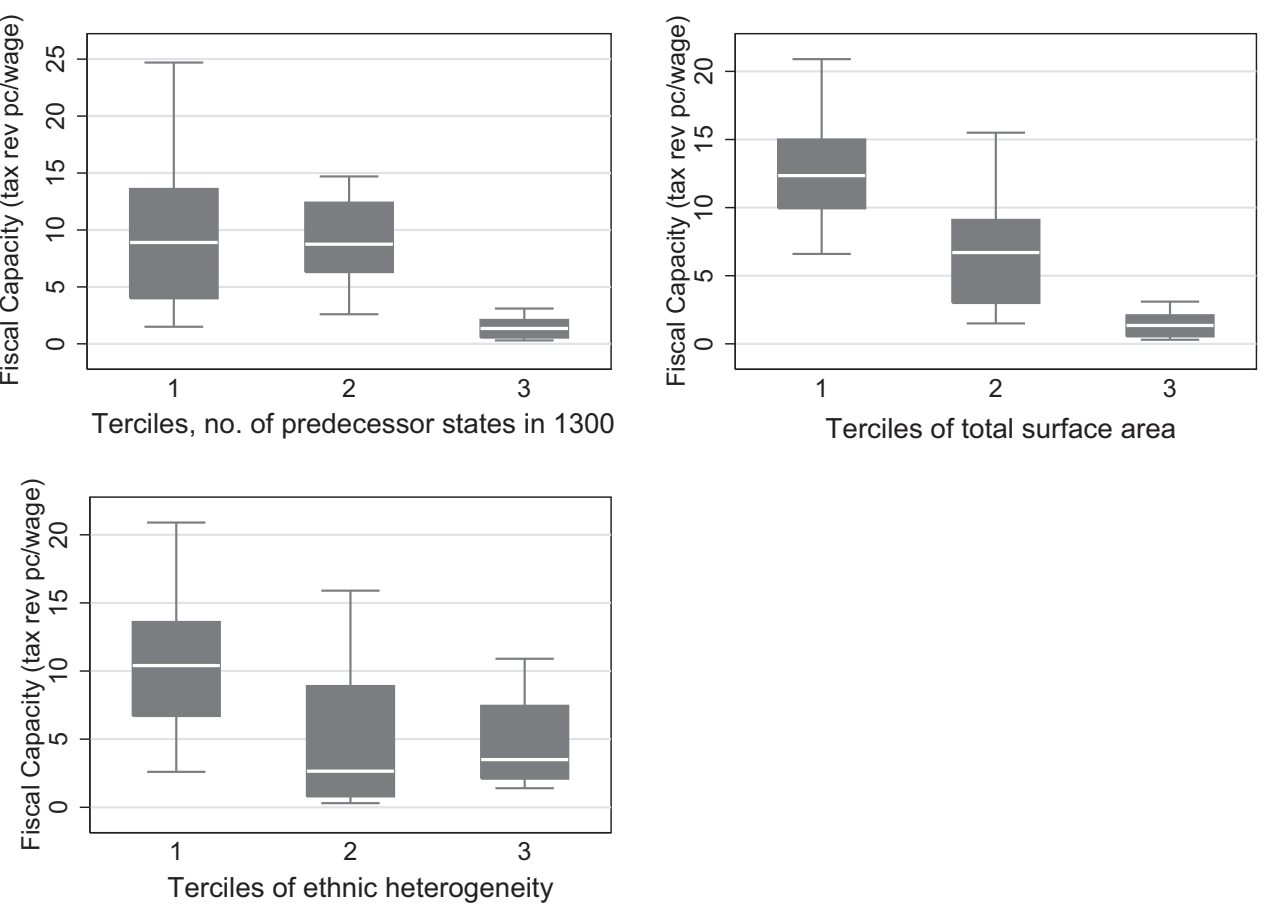

FIGURE 6

Heterogeneity and tax pressure

Notes: The $y$-axis measures average per capita fiscal revenue as a multiple of the average daily urban wage. The $x$-axis shows the terciles of the indicator of heterogeneity, ordered from 1 (lowest) to 3 (highest) — the number of predecessor states in the first quadrant, total surface area in the second, and ethnic heterogeneity in the third.

6.2.1. The effect of $\boldsymbol{B}$. We use three indicators of domestic opposition to centralization $B$. First, the number of predecessor states, which proxies for the extent to which local power-holders can resist centripetal forces. For example, much of the difficulty encountered by the Spanish monarchy in raising revenue reflects territorial expansion: Castile paid high taxes, but extending the tax net to other regions only bred secessionist tendencies (Elliott, 1963). Secondly, we use total surface area of each territory as an indicator of potential opposition. Physical distance put severe constraints on an early modern ruler's ability to project power. Larger states are more likely to be culturally and linguistically diverse. Thirdly, we employ ethnic heterogeneity as a proxy for internal fragmentation. Ethnic divisions are well known to be correlated with a host of negative outcomes, including lower state capacity (Alesina and La Ferrara 2005; Herbst 2000). The number of predecessor states in 1300 is our preferred measure of pre-existing cleavages because it does not depend on the endogenous response of state-building and conquest.

We define tax pressure as fiscal revenue per capita as a multiple of the daily urban wage. In this way, our results are not affected by richer countries being able to generate higher fiscal revenues simply because there is more to tax. We pool data for 17 European states over the period 15001780. As a first step, in Figure 6, we examine how tax-raising interacted with the three indicators of potential opposition to centralization-prior territorial divisions in Europe after 1500, surface area, and ethnic heterogeneity. We divide the data into terciles for each of these variables. The 
size of each box indicates the 25th and 75th percentiles, while the median is highlights as the light line inside the box. The "whiskers" show the rest of the distributional range. There is a clear inverse pattern between the number of predecessor states on a country's territory and the average tax take. The only states with substantial tax pressure are in the lowest quintile of the number of predecessor states. At the opposite end of the spectrum, amongst those states with a high number of predecessors, the average tax take was very low, and there was little variation overall. This suggests that ruling a territory with few predecessor states was a necessary, but not a sufficient condition for raising high levels of revenue.

Similar patterns emerge for the other two measures of fragmentation-territorial size and ethnic heterogeneity. No large states succeeded in raising high levels of per capita revenue, and average tax revenue in the highest tercile of ethnic fractionalization is low. In Table $\mathrm{C} 2$ in Appendix C, we show the strength of this pattern of association in statistical terms.

6.2.2. The effects of $\lambda$ and B. Our theory predicts that as battlefield success came to depend more and more on fiscal strength, state-building accelerated. At the same time, many variables changed at the time of the Military Revolution. Growing state capacity overall could be explained by all of them. What distinguishes our model from the predictions of, say, Besley and Persson (2009), is that powers may rationally "drop out" of the competition. That is, when money becomes very important for military success, structurally weaker powers may fall behind and even reduce their state-building efforts. In this section, we show some evidence supporting this prediction of our model.

We use three measures of heterogeneity discussed above-total surface area, linguistic fragmentation, and the number of predecessor states. We standardize all variables to have zero mean and a standard deviation of unity, and sum the values for each country (Sum).

As a first pass to illustrate how fiscal performance changed over time, we calculate changes in tax pressure (Table 4). In particular, consider the drastic cases in which countries actually experience a drop in tax pressure, meaning that relative to incomes, the government generated less revenue on average in a given 50-year period compared to the preceding period-an extreme form of "giving up" in terms of state-building efforts. As panel A shows, the probability of a decline increases as military conflicts intensifies along the money dimension. After 1650, the probability of giving up goes up by more than $12 \%$ for both homogeneous and divided states in a given 50-year period. This is consistent with the idea that greater external competition actually reduces state-building in some states, generating strong divergence. Interestingly, and in line with our model's predictions, heterogeneous states have the highest probability of experiencing a decline in tax pressure.

In panel $\mathrm{B}$, we look at relative performance in each period. We standardize percentage changes in tax pressure in each period to have zero mean and unit standard deviation. A positive number means that a country raised tax pressure relative to the preceding period more than its competitors. Once again, the evidence is consistent with our model: before 1650, countries with low fractionalization actually lagged behind their highly fragmented competitors in terms of revenue raising (in a typical period, they raised their tax pressure by $14 \%$ less than highly fragmented states). Because, as we just saw, homogenous states have higher levels of taxation ability, this suggests that before 1650 there was some convergence among cohesive and divided countries. There is a striking reversal in the pattern after 1650 - then, the low fractionalization powers were raising tax pressure much more than the less homogenous powers (relative difference $38 \%$ ). This evidence is indicative of strong divergence post 1650, consistent with our model.

Finally, we check one additional prediction that differentiates our model from others-the changing role of frequent military conflict as money sensitivity changes. In particular, our model 
TABLE 4

Relative revenue raising by European powers

\begin{tabular}{|c|c|c|}
\hline \multicolumn{3}{|c|}{ Panel A: Probability of declining tax pressure } \\
\hline & $\begin{array}{l}\text { Low fraction } \\
\operatorname{Sum}^{H}=0\end{array}$ & $\begin{array}{l}\text { High fraction } \\
\operatorname{Sum}^{H}=1\end{array}$ \\
\hline Pre-1650 & 0 & 0.125 \\
\hline Post-1650 & 0.125 & 0.33 \\
\hline \multicolumn{3}{|c|}{ Panel B: Standardized revenue growth } \\
\hline & $\mathrm{Sum}^{H}=0$ & $\mathrm{Sum}^{H}=1$ \\
\hline Pre-1650 & -0.14 & 0.22 \\
\hline Post-1650 & 0.13 & -0.25 \\
\hline \multicolumn{3}{|c|}{ Panel C: Standardized revenue growth when war frequency $>$ mean } \\
\hline & $\operatorname{Sum}^{H}=0$ & $\operatorname{Sum}^{H}=1$ \\
\hline Pre-1650 & -0.65 & -0.57 \\
\hline Post-1650 & 0.11 & -0.49 \\
\hline \multicolumn{3}{|c|}{$\begin{array}{l}\text { Notes: Panel A: we define a decline in tax pressure as a negative change } \\
\text { in total fiscal revenue, calculated as a multiple of the daily urban wage, } \\
\text { between each period } t \text { and } t-1 \text {. Panel B: we standardize the distribution } \\
\text { of changes in tax pressure in each period to have a mean of zero and } \\
\text { a standard deviation of unity. Finally, we calculate period averages for } \\
\text { each subgroup. Sum }{ }^{H} \text { is a dummy variable that takes the value of one if } \\
\text { the sum of standardized heterogeneity measures is greater than the mean, } \\
\text { and zero otherwise. For the measures of heterogeneity, see discussion in } \\
\text { the text. Panel C: here, we condition on war frequency in neighbouring } \\
\text { states (excluding wars with the power in question). We examine the part } \\
\text { of the sample with above-average war frequency. }\end{array}$} \\
\hline
\end{tabular}

predicts that when money sensitivity is low, frequent conflict should reduce state-building in all countries. When money sensitivity is high, frequent conflict should induce divergence in state-building between cohesive and divided countries. To test for these predictions, we take as our benchmark of "highly frequent war" the subsample in which was frequency was above average. Because war is endogenous, we use war frequency in neighbouring countries (excluding the country in question) as a conditioning variable. The results are reported in Panel $\mathrm{C}$ above, and they are consistent with the predictions of our model. Before 1650, both high- and lowfragmentation countries fall behind in relative terms if there is frequent war and hence a high risk of being affected itself. Thus, frequent wars indeed seem to have been associated with abnormally low state-building, offering empirical validation for the "tax-like" character of military conflict in a period when money matters less for military success. After 1650, highly fragmented powers continue to fall behind if there is a lot of war amongst their neighbours. Not so among the more homogenous powers - they actually begin to raise revenue more the rest of the sample. This finding is again consistent with our model.

6.2.3. Regression analysis. To systematically assess the link between money sensitivity of war and state-building, we perform a regression analysis where we use as our measure of money sensitivity $\lambda$. Instead of the $\lambda$ for the entire sample period, as estimated in Section 6.1, we generate a time-varying variable $\lambda_{t}$ by regressing battle outcomes on the difference in log incomes period-by-period. The variable, therefore, tracks the rising importance of money in winning on the battlefield. The results are reported in Table 5 . 
TABLE 5

Revenue raising and the military value of money (dependent variable: tax pressure revenue per capita)

\begin{tabular}{|c|c|c|c|c|}
\hline & $\begin{array}{l}(1) \\
\text { OLS }\end{array}$ & $\begin{array}{l}(2) \\
\text { FE }\end{array}$ & $\begin{array}{c}\text { (3) } \\
\text { FE+institutions }\end{array}$ & $\begin{array}{c}\text { (4) } \\
\text { Controls }\end{array}$ \\
\hline \multicolumn{5}{|l|}{ Panel A } \\
\hline$\lambda_{t}$ & $\begin{array}{l}66.45^{* *} \\
(2.85)\end{array}$ & $\begin{array}{l}59.66^{* *} \\
(2.5)\end{array}$ & $\begin{array}{l}57.42^{* *} \\
(2.5)\end{array}$ & $\begin{array}{l}55.47^{* *} \\
(2.75)\end{array}$ \\
\hline ConsExec & & & $\begin{array}{l}1.18^{* *} \\
(2.89)\end{array}$ & \\
\hline Area & & & & $\begin{array}{l}-1.21 e-12 \\
(-1.35)\end{array}$ \\
\hline Slope & & & & $\begin{array}{l}-0.137 \\
(-0.54)\end{array}$ \\
\hline Pop $_{200}$ & & & & $\begin{array}{l}20.64^{* * *} \\
(4.22)\end{array}$ \\
\hline Constant & $\begin{array}{l}-2.9 \\
(0.81)\end{array}$ & $\begin{array}{l}-2.1 \\
(0.59)\end{array}$ & $\begin{array}{c}-2.9 \\
(0.8)\end{array}$ & $\begin{array}{l}-4.8 \\
(1.5)\end{array}$ \\
\hline$N$ & 53 & 53 & 53 & 53 \\
\hline \multirow[t]{2}{*}{$R^{2}$} & 0.11 & 0.74 & 0.76 & 0.62 \\
\hline & $\begin{array}{c}(1) \\
\text { Low-fraction } \\
\text { Sum }^{H}=0\end{array}$ & $\begin{array}{c}(2) \\
\text { High-fraction } \\
\text { Sum }^{H}=1\end{array}$ & $\begin{array}{l}(3) \\
\text { Inter }\end{array}$ & $\begin{array}{c}(4) \\
\text { Inter+FE }\end{array}$ \\
\hline \multicolumn{5}{|l|}{ Panel B } \\
\hline$\lambda_{t}$ & $\begin{array}{l}75.8^{*} \\
(2.4)\end{array}$ & $\begin{array}{l}30.85^{*} \\
(2.2)\end{array}$ & $\begin{array}{l}82.46^{* *} \\
(2.67)\end{array}$ & $\begin{array}{l}75.77^{*} \\
(2.4)\end{array}$ \\
\hline $\mathrm{Sum}^{H}$ & & & $\begin{array}{c}2.5 \\
(0.6)\end{array}$ & \\
\hline$\lambda * \operatorname{Sum}^{H}$ & & & $\begin{array}{l}-56.6^{*} \\
(-2.3)\end{array}$ & $\begin{array}{l}-44.92 \\
(-1.9)\end{array}$ \\
\hline Constant & $\begin{array}{l}-4.8 \\
(-0.97)\end{array}$ & $\begin{array}{l}1.97 \\
(0.9)\end{array}$ & $\begin{array}{c}-3.16 \\
(-0.64)\end{array}$ & $\begin{array}{c}-4.82 \\
(-0.96)\end{array}$ \\
\hline$N$ & 34 & 19 & 53 & 53 \\
\hline$R^{2}$ & 0.64 & 0.77 & 0.39 & 0.75 \\
\hline
\end{tabular}

Notes: $* p<0.1, * * p<0.05, * * * p<0.01 ; t$-statistics in parentheses; $\lambda$ is the estimated slope parameter from a regression of military outcomes on relative fiscal strength, ConsExec is constraints on the executive, Area is the total surface area of a state, Slope is the average slope of terrain (a measure of ruggedness), Pop 200 is the share of the population within $200 \mathrm{~km}$ of the capital, and $\mathrm{Sum}^{H}$ is the sum of standardized measures of fractionalization.

We first show that the data bear out one of the key predictions of our model - that as the military value of money grew, revenue-raising increased. This is true in the simple OLS setup, with country-fixed effects, and controlling for institutional quality (Panel A, columns 1-3). Effects are large. For example, the result in column 2 implies that a one standard deviation increase in the importance of money for victory translates into 0.44 standard deviations higher tax revenues on average-equivalent to a rise by 2.44 daily wages compared to an average of 7.36. In column 3 , we use fixed effects and control for constraints on the executive, along the lines of Acemoglu et al. (2005). In our model, institutions endogenously depend on money sensitivity. By controlling for money sensitivity in column 3, we estimate the independent effect of institutions on revenue raising. Again, we obtain a large and significant coefficient on $\lambda .{ }^{25}$ We also find the same effect after controlling for other factors associated with tax raising (column 4).

25. Figure D1 in Appendix D compares the effect of both variables side-by-side (using the odds ratio as the measure of money sensitivity of war outcomes). While neither explanatory variable captures all of the existing variation, the fit is somewhat tighter in the case of the odds ratio. 
In Panel B, we investigate interaction effects between heterogeneity and the growing importance of fiscal resources for war. We estimate

$$
R_{i, t}=C+\beta B_{i, t}+\delta \lambda_{t}+\rho B_{i, t} \lambda_{t}+\epsilon_{i, t}
$$

where $R_{i, t}$ is tax revenue (relative to average wages in a country $i$ at time $t$ ), which serves as our measure of fiscal capacity, $B_{i, t}$ is our measure of underlying fragmentation, $\lambda_{t}$ is our estimate of the importance of money for military success, and $B_{i, t} \lambda_{t}$ is the interaction of fragmentation and money sensitivity. We use clustered standard errors (at the level of period $t$ ) to deal with the fact that $\lambda_{t}$ vary by period.

In columns 1 and 2 (Table 5), we look at countries with low and high pre-existing heterogeneity. In both groups, tax revenue was systematically higher in periods when the military value of money was higher. However, the effect is more than three times bigger for the low-heterogeneity part of the sample. In columns 3 and 4, we investigate if this difference in slopes is statistically significant. Without country-fixed effects (column 3), we find a large and significant coefficient for the interaction term, as well as a negative coefficient on high fragmentation itself. In column 4 , the high- fragmentation dummy drops out because we are estimating with fixed effects; the coefficient of the interaction term is marginally smaller and slightly below the threshold for $10 \%$ significance. The interaction results in columns 3 and 4 bear out one of the key predictions of our model - that, at sufficiently high levels of fragmentation, increases in the usefulness of money for fighting war leads to lower fiscal effort (reinforcing the evidence in Table 4). As the Military Revolution unfolded, states with a higher $B$ - underlying heterogeneity-increasingly dropped out of the race to raise tax revenues.

A simple way to summarize the cross-sectional patterns in the data is to examine, state-bystate, the extent to which the military importance of money predicts state-building. To this end, we regress - separately for each country-fiscal capacity on $\lambda$. This yields a country-specific response to overall changes in the military importance of money. Figure 7 plots the estimated coefficients from these regressions alongside the composite measure of fragmentation. Overall, there is a strong inverse pattern: For the set of countries in the sample overall, the correlation coefficient is -0.74 . The only states with a high responsiveness to growing $\lambda$ all have relatively low levels of fragmentation-like England and Prussia. Countries with intermediate levels of fragmentationlike Austria-showed positive responses, but smaller ones than the highly homogenous powers. Finally, weak and highly fragmented states like Poland and the Ottoman Empire show barely any association between revenue raising and the military value of money.

6.2.4. Instrumental variable results. Finally, our model predicts that a more belligerent environment may be associated with greater state-building, especially as the value of money for battlefield success rises. Taking this prediction to the data is complicated by the fact that war is endogenous; it is a choice variable, which depends on fiscal revenue because fiscal strength is a predictor of military success.

To sidestep the issue of reverse causation we focus on an alternative measure of belligerencethe frequency of war in neighbouring states (excluding the country itself). War in Europe came in waves; for example, the maelstrom of the Thirty Years War eventually drew in powers that had initially avoided participating. More frequent war in neighbouring states during the same period should have heightened the expectation of rulers that they, too, might be affected by war.

In Table 6, we use war frequency in neighbouring states during the same period as an instrument for fiscal revenue (columns 1 and 3). We find a strong and significant effect in a simple OLS setup, for two dependent variables - tax pressure (TP), the ratio of per capita tax revenue and countryspecific wages, and revenue per capita, measured in grams of silver (RevenuеPC). Next, we use 

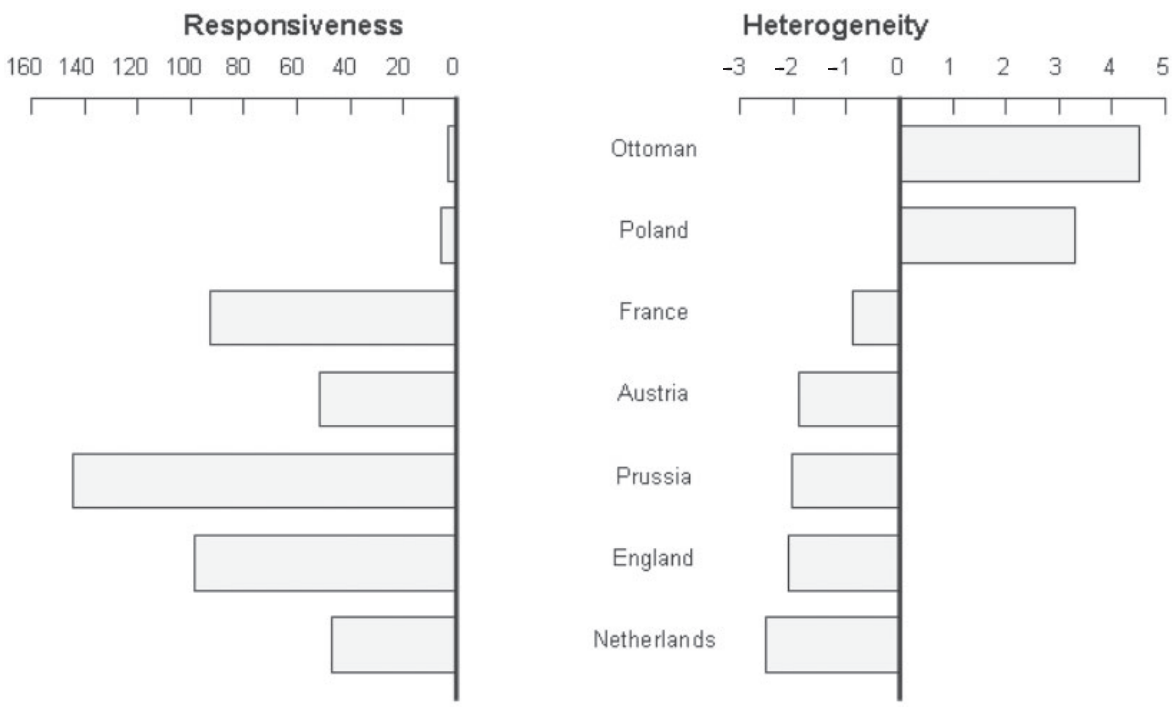

FIGURE 7

Revenue raising and the military value of fiscal revenue

Notes: The left plot shows the country-specific sensitivity of revenue-raising to $\lambda$, the value of money in winning wars. The corresponding regressions are run separately for each country, with our time-varying measure of $\lambda$. The second plot gives the aggregate measure of fragmentation for each country.

TABLE 6

War and revenue raising (OLS and IV-results)

\begin{tabular}{|c|c|c|c|c|}
\hline \multirow[b]{2}{*}{$\begin{array}{l}\text { Dependent variable } \\
\text { estimator }\end{array}$} & (1) & (2) & (3) & (4) \\
\hline & \multicolumn{2}{|c|}{ Tax Pressure } & \multicolumn{2}{|c|}{ RevenuePC } \\
\hline \multicolumn{5}{|l|}{ Second Stage/OLS } \\
\hline WarFreq & $\begin{array}{l}5.54 * * \\
(2.25)\end{array}$ & $\begin{array}{l}17.2 * * \\
{[0.03]}\end{array}$ & $\begin{array}{l}57.1 * * * \\
(3.31)\end{array}$ & $\begin{array}{r}137.26 * * * \\
{[0.0066]}\end{array}$ \\
\hline \multicolumn{5}{|l|}{ FirstStage } \\
\hline WarNeighbour & & $\begin{array}{c}0.32 \\
(1.53)\end{array}$ & & $\begin{array}{l}0.414 * * \\
(2.11)\end{array}$ \\
\hline$N$ & & 45 & & 54 \\
\hline$R^{2}$ & 0.095 & & 0.13 & \\
\hline
\end{tabular}

Notes: $* p<.01,{ }^{*} p<<0.05, * * * p<0.01 ; t$-statistics in parentheses for OLS and the first stage; for the second stage under IV, we report Anderson-Rubin $p$-values: WarFreq is the frequency of warfare in each 50-year period in each country, WarNeighbour is the frequency of war amongst immediately adjacent states in the same period (excluding wars of the country in question).

war frequency in neighbouring states as an instrument to predict war frequency in the country in question. The exclusion restriction is that there is no effect of war frequency in neighbouring country $j$ on fiscal capacity in country $i$ that is not a result of the risk of war. As the AndersonRubin test statistics show, war in neighbouring states is a strong predictor of war in each individual country. The size of the coefficient grows as we use IV, which suggests that the relevant part of the variation identified by our instrument-fiscal capacity increases driven by the threat of war 
as a result of other powers' belligerence-is more strongly associated with revenue-raising than simple war frequency in a country itself. Our findings strongly suggest that there is a link between increasing state capacity and the frequency of war in early modern Europe-and the IV results show that the part of the variation reflecting the risk of war is highly correlated with fiscal revenue increases.

\section{CONCLUSION}

Does frequent warfare lead to more state-building? We argue that the emergence of such a link reflects the importance of money for military success - the direct result of changes in military technology in Europe after 1500. To analyse these effects, we build a simple model of statebuilding, and then examine the effects of war in a two-player setting. The need to finance war makes money more valuable, increasing the benefits of greater state-building. When war becomes very costly, the stronger, less fragmented power will invest in greater state capacity because of the threat of war. Weaker powers then rationally drop out of the competition.

Our empirical results underscore the importance of the Military Revolution. The chances of a richer power winning a battle were no greater than those of poorer powers. By the end of the early modern period, richer belligerents won wars with a much higher probability. We find that as military technology changed, so did state-building. In particular, after the Military Revolution, intense military conflict was associated with strong state consolidation in some cohesive countries, and weaker consolidation-or even reductions in fiscal capacityin domestically divided countries. After 1650, with the Military Revolution at its peak, more fragmented powers were almost three times as likely to witness a decline in tax pressure than their more homogenous rivals.

Our analysis is not meant to explain patterns of state-building in all countries and periods. The unification of both Italy and Germany took place after our period. One was the result of conquest by the militarily dominant power, Piedmont, while the other came about after victories against external enemies by the strongest national military power, Prussia. In both cases, high taxgenerating abilities went hand-in-hand with a substantial edge in military capability. In both cases, several of the smaller powers who lost their independence had long given up competing militarily with the dominant power. At the same time, it is worth pointing out the limits of comparability. Military force after the French Revolution relied on mass armies to a greater extent than before the 18th century; the ability to conscript and use large bodies of armed men required political and institutional innovations that were beyond the considerations of Louis XIV and Frederick the Great (Ticchi and Vindigni, 2008; Dincecco et al., 2011).

The predictions of our theory are also in line with the basic patterns of state-building in the great empires-Rome, Ming Dynasty China, and the Ottoman Empire. Military technology was vastly different in all these cases, and there was less of a need to create military might with tax revenue. ${ }^{26}$. As our theory would predict, neither evolved a highly centralized structure of government or high levels of uniform tax collection. With each conquest, the Ottoman Empire simply took over the existing tax structure, with no attempt at imposing uniformity and centralization of collection powers (Vryonis, 1969). Over time, individual provinces of the Ottoman Empire became selfgoverning in all but name. Similarly, Roman rule typically showed a strong aversion to centralized, direct rule, delegating governance to local elites unless direct challenges to Roman supremacy dictated otherwise (Kelly, 2006). During both the Republic and the Empire, there was no uniform

26. One key factor was that both the Ottoman Empire and Ming China faced a threat from nomads, against whom gunpowder technology was much less effective. Cf. Hoffman (2012). 
system of taxation; instead, each province and city had its own set of dues, often targeting local products such as fishing or salt production (Ando, 2006).

Ming China is also a case in point. Facing few external military threats, overall levels of taxation were low, too (and lower than under the previous dynasty). Centralization was conspicuous by its absence, with villages being off-limits to imperial officials and with the imperial treasury functioning more like a "general accounting office than an operating agency" (Huang 1998). Tax assessment and collection were left to lower levels of government, with few attempts to collect information or impose uniform taxes (Huang 1998): "Control over the empires fiscal data became perfunctory; most territorial units simply resubmitted their earlier reports as the new returns. Since tax deliveries were largely carried out at the lower levels of the government, the capacity at the middle echelon of the fiscal administration to deal with logistic matters was never fully developed."

There are alternatives to our interpretation of the rise of states after 1500. One emphasizes the importance of the Black Death. After 1349, per capita incomes surged, and rulers' tax revenue increased. Since war was a "superior good" for princes, larger tax revenues, and higher war frequency went hand-in-hand (Voigtländer and Voth, 2013). We do not dispute the individual elements of this story, which likely contributed to the confluence of economic success and statebuilding in early modern Europe, nor the fact that greater riches could have translated into more frequent wars. However, as the data on tax pressure indicate, the growth of fiscal revenue was far greater than can be explained by higher per capita incomes. Also, there is an important divergence in the cross-section of countries. These two facts are easier to explain in our model.

\section{APPENDIX}

\section{A. PROOFS}

Proof of Lemma 1. We now show that the symmetric equilibrium of Lemma 1 where only local production occurs always exists. Suppose that we are in such an equilibrium $\left(\tau_{l, d}, \tau_{m, d}\right)$ and suppose that at the tax rate $\tau_{m, d}$ market production is less profitable than home production, namely $\max \left[0,\left(1-2 \tau_{m, d}\right)\right] A_{m}<A_{h}$. Is it profitable for power holder $i$ to deviate to a tax rate $\tau_{m, i}$ at which market production is profitable again? The maximal tax at which the power holder of district $i$ can induce market production is equal to:

$$
\tau_{m, i}=1-\tau_{m, d}-\frac{A_{h}}{A_{m}} .
$$

If $\tau_{m, d} \geq\left(A_{m}-A_{h}\right) / A_{m}$, the above expression is negative, so it is unprofitable for the local power holder $i$ to deviate. If $\tau_{m, d}<\left(A_{m}-A_{h}\right) / A_{m}$, the tax is positive and-by fostering market production in the adjacent district-it yields a tax revenue equal to:

$$
2 A_{m} \tau_{m, i}=2 A_{m}\left(1-\tau_{m, d}\right)-2 A_{h},
$$

which is less than the rent $\left(A_{l}-A_{h}\right)$ that the power holder obtains in Lemma 1 (so that the deviation is not profitable) provided:

$$
\tau_{m, d}>1-\frac{A_{l}+A_{h}}{2 A_{m}}
$$

Thus, the equilibrium of Lemma 1 exists for all parameter values.

Proof of Proposition 1. Denote by $\Pi^{j}\left(R_{j}, R_{i}\right)$ the payoff of ruler $j=H, F$ as a function of the revenue $R_{i}$ chosen by ruler $i \neq j$.

The first-order condition for ruler $i$ is equal to $\Pi_{R_{i}}^{i}\left(R_{i}, R_{j}\right)=0$ for $i=H, F$. The second-order condition is $\Pi_{R_{i} R_{i}}^{i}\left(R_{i}, R_{j}\right)<0$. For brevity, we analyse these conditions only for the case of ruler $H$. The analysis for ruler $F$ follows straightforwardly. As a preliminary step, recall that $p=L_{H}^{\alpha} R_{H}^{\lambda} /\left(L_{H}^{\alpha} R_{H}^{\lambda}+L_{F}^{\alpha} R_{F}^{\lambda}\right)$ is the win probability of $H$.

Plugging equation (4.1) into equations (4.5) and (4.6), we find that the first-order condition for ruler $H$ is equal to:

$$
\theta \frac{\lambda}{R_{H}} p(1-p)\left(R_{H}+R_{F}\right)+\theta p+2(1-\theta)-2 c_{H} R_{H}=0 .
$$

The second-order condition of the problem is in turn equal to:

$$
-\theta \frac{\lambda}{R_{H}^{2}} p(1-p)[1+\lambda(2 p-1)]\left(R_{H}+R_{F}\right)+2 \theta \frac{\lambda}{R_{H}} p(1-p)-2 c_{H}<0 .
$$


When $\lambda \leq 1$ the second-order condition is globally satisfied. By plugging the expression for $\left(\lambda / R_{H}\right) p(1-p)$ from equation (A.1) into equation (A.2) we can see that $[1+\lambda(2 p-1)]>0$. Furthermore, the term $\theta\left(\lambda / R_{H}\right) p(1-p)-c_{H}$ can be shown to be always negative by plugging into equation (A.2) the expression for $2 c_{H}$ from equation (A.1). Thus, $\lambda \leq 1$ is sufficient for the existence and uniqueness of an optimum. See Hirai and Szidarovszky (2013) for a similar point. [Note: To show that equation (A.1) identifies a unique best response $R_{H}\left(R_{F}\right)$, we must still show that $R_{H}(0)$ is positive and finite. It is easy to see that this is the case because $R_{H}(0)=(1-\theta / 2) / c_{H}>0$.]

To see that the equilibrium exists and is unique, consider the reaction functions. By applying the implicit function theorem to equations (4.5) and (4.6), and by considering the analogous expressions for ruler $F$, we have that:

$$
\begin{aligned}
& \frac{d R_{H}\left(R_{F}\right)}{d R_{F}}=-\frac{\Pi_{R_{F} R_{H}}^{H}}{\Pi_{R_{H} R_{H}}^{H}}=-\frac{(\theta / 2)\left[p_{H F}\left(R_{H}+R_{F}\right)+p_{H}+p_{F}\right]}{(\theta / 2)\left[p_{H H}\left(R_{H}+R_{F}\right)+2 p_{H}\right]-1 / R_{H, \text { aut }}}, \\
& \frac{d R_{F}\left(R_{H}\right)}{d R_{H}}=-\frac{\Pi_{R_{F} R_{H}}^{F}}{\Pi_{R_{F} R_{F}}^{F}}=\frac{(\theta / 2)\left[p_{H F}\left(R_{H}+R_{F}\right)+p_{H}+p_{F}\right]}{(\theta / 2)\left[-p_{F F}\left(R_{H}+R_{F}\right)-2 p_{F}\right]-1 / R_{F, \text { aut }}} .
\end{aligned}
$$

The denominator of both expressions is negative by concavity $\left(p_{J . J^{\prime}}\right.$ denotes the second derivative of the win probability of $H$ ). Thus, reaction functions have opposite signs, $\operatorname{sign}\left(\frac{d R_{H}\left(\left.R_{F}\right|^{\cdot}\right)}{d R_{F}}\right)=-\operatorname{sign}\left(\frac{d R_{F}\left(\left.R_{H}\right|^{\cdot}\right)}{d R_{H}}\right)$.

Given that the reaction function $R_{i}\left(R_{j}\right)$ is well defined, an interior equilibrium $\left(R_{H}^{*}, R_{F}^{*}\right)$ is then identified by the equation:

$$
\left\{1+(\theta / 2)\left[-p_{F}\left(R_{H}\left(R_{F}^{*}\right)+R_{F}^{*}\right)-p-1\right]\right\}-\frac{R_{F}^{*}}{R_{F, \text { aut }}}=0
$$

together with $R_{H}^{*}=R_{H}\left(R_{F}^{*}\right)$. Equation (A.5) is simply the first-order condition of ruler $F$ and can be solved for the equilibrium $R_{F}^{*}$.

Consider now the slope of equation (A.5) with respect to $R_{F}^{*}$. The derivative of the left-hand side with respect to $R_{F}^{*}$ is equal to:

$$
\left|\Pi_{R_{F}^{*} R_{F}^{*}}^{F}\right| \frac{d R_{F}\left(R_{H}^{*}\right)}{d R_{H}^{*}} \cdot \frac{d R_{H}\left(R_{F}^{*}\right)}{d R_{F}^{*}}+\Pi_{R_{F}^{*} R_{F}^{*}}^{F} .
$$

At an interior equilibrium $\left(R_{F}^{*}, R_{H}^{*}\right)$, the above equation is negative, because the reaction functions have opposite slopes, $\frac{d R_{F}\left(R_{H}^{*}\right)}{d R_{H}^{*}} \cdot \frac{d R_{H}\left(R_{F}\right)}{d R_{F}^{*}} \leq 0$, and the problem is concave, $\Pi_{R_{F}^{*}}^{F} R_{F}^{*}<0$. The fact that equation (A.6) always crosses zero from above implies that the equilibrium, if exists, is unique.

The equilibrium exists provided $\Pi_{R_{F}}^{F}\left(R_{H}(0), 0\right)>0$ (which can be easily verified to hold) and $\Pi_{R_{F}}^{F}\left(R_{H}\left(A_{m}-\right.\right.$ $\left.\left.A_{h}\right), A_{m}-A_{h}\right) \leq 0$. Consider the latter condition. If $c_{F}<c_{H}$, the reaction function of country $F$ is negatively sloped (this is proved below). As a result, existence is guaranteed provided $\Pi_{R_{F}}^{F}\left(0, A_{m}-A_{h}\right)<0$. This always holds given our assumption that in autarky centralization is partial. If instead $c_{F}>c_{H}$, the reaction function of country $F$ is positively sloped (again, see below). Now existence requires $\Pi_{R_{F}}^{F}\left(A_{m}-A_{h}, A_{m}-A_{h}\right)<0$. This holds if and only if $c_{F}\left(A_{m}-A_{h}\right) \equiv \frac{B\left(A_{l}-A_{h}\right)}{\left(A_{m}-A_{h}\right)}>1+\frac{\theta}{4}(\lambda-3)$, which always holds for $\lambda \gtrless 1$.

When countries are symmetric, they face the same win probability $p=1-p=1 / 2$ and set revenues:

$$
R_{H}^{*}=R_{F}^{*}=R_{\text {aut }}\left[1+\frac{\theta}{4}(\lambda-3)\right] .
$$

Consider now asymmetric countries, $c_{H} \neq c_{F}$. In this case, equations (4.5) and (4.6) imply that in equilibrium we have:

$$
\begin{gathered}
c_{H}=\frac{1+\frac{\theta}{2}\left[\frac{\lambda p(1-p)}{R_{H}}\left(R_{H}+R_{F}\right)-2+p\right]}{R_{H}}, \\
c_{F}=\frac{1+\frac{\theta}{2}\left[\frac{\lambda p(1-p)}{R_{F}}\left(R_{H}+R_{F}\right)-1-p\right]}{R_{F}} .
\end{gathered}
$$

When $c_{H}<c_{F}$, the right-hand side of equation (A.6) is smaller than the right-hand side of equation (A.7). One can show that this condition is equivalent to:

$$
\left(R_{H}-R_{F}\right)\left[(1-\theta)+\frac{\theta}{2} \lambda p(1-p) \frac{\left(R_{H}+R_{F}\right)^{2}}{R_{H} R_{F}}\right]+\frac{\theta}{2}\left[R_{H}(1-p)-R_{F} p\right]>0 .
$$

For $\lambda \leq 1$, the above condition can only be met if $R_{H}>R_{F}$. Thus, when $c_{H}<c_{F}$, an interior equilibrium must feature $R_{H}^{*}>R_{F}^{*}$. Consider next some comparative statics. By differentiating the rulers' first-order conditions, we obtain:

$$
\begin{aligned}
& \Pi_{R_{H} R_{H}}^{H} d R_{H}+\Pi_{R_{H} R_{F}}^{H} d R_{F}=R_{H} d c_{H}, \\
& \Pi_{R_{F} R_{H}}^{F} d R_{H}+\Pi_{R_{F} R_{F}}^{F} d R_{F}=R_{F} d c_{F}
\end{aligned}
$$


By solving the linear system it is easy to see that:

$$
\begin{aligned}
& d R_{H}=-\varphi R_{H} d c_{H}-\varphi \frac{\Pi_{R_{H} R_{F}}^{H}}{\left|\Pi_{R_{F} R_{F}}^{F}\right|} R_{F} d c_{F}, \\
& d R_{F}=-\varphi \frac{\left|\Pi_{R_{H} R_{H}}^{H}\right|\left|\Pi_{R_{F} R_{F}}^{F}\right|}{\left|\Pi_{R_{F} R_{F}}^{F}\right|^{2}} R_{F} d c_{F}-\varphi \frac{\Pi_{R_{F} R_{H}}^{F}}{\left|\Pi_{R_{F} R_{F}}^{F}\right|} R_{H} d c_{H}
\end{aligned}
$$

where $\varphi=\frac{\left|\Pi_{R_{F} R_{F}}^{F}\right|}{\left|\Pi_{R_{H} R_{H}}^{H} \Pi_{R_{F} R_{F}}^{F}\right|+\left|\Pi_{R_{H} R_{F}}^{H} \Pi_{R_{F} R_{H}}^{F}\right|}>0$.

Centralization in $J$ decreases with its cost, i.e. $\frac{d R_{H}}{d c_{H}}<0$ and $\frac{d R_{F}}{d c_{F}}<0$. On the other hand, an increase in the cost of centralization in country $J$ boosts centralization in country $-J$, namely $\frac{d R_{-J}}{d c_{J}}>0$ if and only if the reaction function of country $-J$ is negatively sloped, namely $\frac{d R_{-J}\left(R_{J}\right)}{d R_{J}}<0$. To see which of the two countries reduces centralization when the cost of centralization declines abroad, (namely $\frac{d R_{-J}}{d c_{J}}>0$ ), consider the mixed derivative of country $-J$, where we have w.l.o.g. taken $-J=H$. After some algebra, one finds that:

$$
\Pi_{R_{H} R_{F}}^{H} \propto-\lambda(1-2 p) \frac{R_{H}+R_{F}}{R_{H} R_{F}}+\frac{1}{R_{H}}-\frac{1}{R_{F}} .
$$

The above expression is negative (so that $\frac{d R_{H}}{d c_{F}}>0$ ) provided:

$$
\lambda \frac{R_{H}^{\lambda}-R_{F}^{\lambda}}{R_{H}^{\lambda}+R_{F}^{\lambda}} \leq \frac{R_{H}-R_{F}}{R_{H}+R_{F}} .
$$

The left-hand side is an increasing function of $\lambda$ provided $R_{H}>R_{F}$. As a result, when $\lambda \leq 1$ the above condition holds if an only if $R_{H}>R_{F}$ which, by the previous result amounts to $c_{H}<c_{F}$.

To conclude the proof, we now prove the properties discussed in the text for the case in which $\lambda>1$. In this case, the equilibrium may not exist or fail to be unique. Suppose however that countries are symmetric, namely, and that a symmetric equilibrium exists. Then, it is easy to see that the symmetric revenues $\left(R_{H}, R_{F}\right)$ above identify such symmetric equilibrium, for they satisfy both the first- and the second-order condition of the rulers' optimization problem. It is then evident that at these revenues state-building increases in $\theta$ provided $\lambda>3$.

Suppose now that countries are asymmetric and that an asymmetric equilibrium exists that is identified by the rulers' first- and second-order condition. In this case, equations (A.10) and (A.11) pin down the comparative statics of equilibrium revenues. As a result, the sign of $\Pi_{R_{H} R_{F}}^{H}$ and thus the sign of $\frac{d R_{H}}{d c_{F}}$ is reversed.

Proof of Proposition 2. When $\gamma=1$, the rulers' problem is concave, in the sense that the second-order condition is satisfied, provided $\theta \cdot \lambda<\min _{J} c_{J}$, which identifies the condition in the proposition $\lambda<\min _{J} c_{J} / \theta$. In this case, the reaction functions yield:

$$
R_{J}^{*}=\min \left[\left(\frac{1-3 \theta / 4}{1-\lambda \theta / c_{J}}\right) \cdot\left(1 / c_{J}\right),\left(A_{m}-A_{h}\right)\right]
$$

The revenues in the above equation are higher than autarky revenues provided $\lambda>(3 / 4) c_{J}$. As a result, the condition ensuring concavity $\lambda<\min _{J} c_{J} / \theta$ is weak: even if war occurs for sure, $\theta=1$, the condition is consistent with levels of $\lambda$ such that the war threat boosts fiscal revenues relative to autarky.

Using equation (A.12) is also straightforward to uncover the property in Point (3) of Proposition 2. When centralization is partial in all countries, namely $R_{J}^{*}<\left(A_{m}-A_{h}\right)$ for $J=H, F$, we have that:

$$
\frac{R_{H}^{*}}{R_{F}^{*}}=\frac{c_{F}}{c_{H}} \cdot \frac{1-\lambda \theta / c_{F}}{1-\lambda \theta / c_{H}},
$$

which is higher than 1 and increases in $\lambda \theta$ if and only if $c_{H}<c_{F}$.

Equation (A.12) describes equilibrium revenues only when both countries win with some probability. An equilibrium $\left(R_{H}, R_{F}\right)$ where one country wins with probability one does not in fact exist because the payoff of the losing country is convex around such equilibrium, so that it always has an incentive to deviate from it. To see this, suppose that $-J$ is the strong country and wins with probability one, namely:

$$
-\frac{1}{2}+\lambda\left(R_{J}-R_{-J}\right)=0
$$

To fulfil this constraint, the weak country $J$ must find it unprofitable to deviate both to: (i) a slightly higher revenue (which allows the country to win with small but positive probability), and (ii) a slightly lower revenue (at which country $J$ has still zero probability of winning but saves some costs of centralization). The marginal benefit of setting revenues 
slightly above $R_{J}$ is $\theta\left[1 / 2+2 \lambda R_{J}\right]+2(1-\theta)-C^{\prime}\left(R_{J}\right)$, where $C^{\prime}\left(R_{J}\right)$ is the marginal cost of raising revenues at the equilibrium point. The marginal benefit of setting revenues below $R_{J}$ is $-2(1-\theta)+C^{\prime}\left(R_{J}\right)$. It is easy to see that, since $C^{\prime}\left(R_{J}\right)$ is increasing, it is not possible to find a value of $R_{J}$ such that both deviations are unprofitable.

Consider now the conditions guaranteeing that the equilibrium exists, namely that win probabilities are interior. We will look for conditions under which this is the case for any $\lambda$. To do so, denote by the $c \equiv c_{-J}$ the cost parameter of the strong country and $z c \equiv c_{J}$ the cost parameter of the weak country, where $z>1$ increases in the inequality between countries.

By using Equation (A.12), it is easy to see that the value of $\lambda$ at which the revenue difference between countries is maximized is the one at which the strong ruler $-J$ centralizes fully, attaining $R_{-J}=\left(A_{h}-A_{h}\right)$. This level is identified by $\lambda^{*} \equiv \frac{\left(A_{m}-A_{h}\right) c-(1-3 \theta / 4)}{\left(A_{m}-A_{h}\right)}$. At this level of money sensitivity, the strong country $-J$ wins with probability less than one provided:

$$
\lambda^{*}\left[\left(\frac{1-3 \theta / 4}{c-\theta \lambda}\right)-\left(\frac{1-3 \theta / 4}{z c-\theta \lambda}\right)\right]=\frac{1}{2} .
$$

After some algebra, it is immediate to see that the above condition is satisfied provided $z<\bar{z}$, where $\bar{z}>1$ is a given threshold. This provides the bound on country inequality in domestic divisions that guarantees that for all values of $\lambda$ win probabilities are interior and a quinqu equilibrium exists.

Proof of Corollary 1. Denote autarky revenues in the two countries by $\left(R_{H, \text { aut }}, R_{F, \text { aut }}\right)$. We continue to assume heterogeneity and $\lambda$ are sufficiently small that the problem is concave and interior. Then, an interior equilibrium occurs at the intersection of the reaction functions:

$$
\begin{aligned}
& R_{H}\left(R_{F} \mid \theta, c_{H}\right)=\left(\frac{1-3 \theta / 4}{1-\theta \lambda / c_{H}}\right) \cdot R_{H, a u t}+\frac{\theta(1-\gamma) \lambda / c_{H}}{1-\theta \lambda / c_{H}} \cdot R_{F}, \\
& R_{F}\left(R_{H} \mid \theta, c_{F}\right)=\left(\frac{1-3 \theta / 4}{1-\theta \lambda \gamma / c_{F}}\right) \cdot R_{F, a u t}-\frac{\theta(1-\gamma) \lambda / c_{F}}{1-\theta \lambda \gamma / c_{F}} \cdot R_{H} .
\end{aligned}
$$

The intercept captures the reform chosen by a ruler when his opponent does not reform at all (i.e. when $R_{-J}=0$ ), the second term captures a ruler's reaction to state-building abroad. Notice that here two reaction functions have opposite slopes, and the reaction function of the country with a larger army has a positive slope. By solving the above two-equations system we find:

$$
\begin{aligned}
& R_{H}(\lambda)=(1-3 \theta / 4) \frac{\left(c_{F}-\theta \lambda \gamma\right)+(1-\gamma) \theta \lambda}{\left(c_{F}-\theta \lambda \gamma\right)\left(c_{H}-\theta \lambda\right)+(1-\gamma)^{2} \theta^{2} \lambda^{2}}, \\
& R_{F}(\lambda)=(1-3 \theta / 4) \frac{\left(c_{H}-\theta \lambda\right)-(1-\gamma) \theta \lambda}{\left(c_{F}-\theta \lambda \gamma\right)\left(c_{H}-\theta \lambda\right)+(1-\gamma)^{2} \theta^{2} \lambda^{2}} .
\end{aligned}
$$

From the above expressions one can readily obtain that:

$$
\frac{R_{H}(\lambda)}{R_{F}(\lambda)}=\frac{R_{H, \text { aut }}}{R_{F, \text { aut }}} \cdot \frac{1+\theta \lambda R_{F, \text { aut }}(1-2 \gamma)}{1-\theta \lambda R_{H, \text { aut }}(2-\gamma)} .
$$

This expression implies that if $H$ is the more cohesive country, so that $R_{H, \text { aut }}>R_{F, \text { aut }}$, then external war threats $(i . e$. any $\theta>0$ ) increase $R_{H}(\lambda) / R_{F}(\lambda)$ above the autarky level and this ratio increases in money sensitivity $\lambda$. Furthermore, inspection of the "weak" ruler's revenue $R_{F}(\lambda)$ reveals that:

$$
\frac{d R_{F}(\lambda)}{d \lambda}<0 \Leftrightarrow \theta \gamma\left(c_{H}-\theta \lambda\right)^{2}<(1-\gamma) \theta\left\{\left(c_{F}-\theta \lambda \gamma\right)\left(c_{H}-\theta \lambda\right)+\theta \lambda\left[\left(c_{F}-\theta \lambda \gamma\right)+\gamma\left(c_{H}-\theta \lambda\right)\right]\right\},
$$

which is fulfilled provided $\gamma$ is sufficiently small (provided of course the rulers' problem is concave). It is easy to check that-provided again that the rulers' problem is concave- $R_{H}(\lambda)$ is an increasing function for $\gamma$ sufficiently close to 0 . As a result, there exists a threshold $\widehat{\gamma}$ such that, for $\gamma<\widehat{\gamma}$, the revenue of the strong country $H$ increases in $\lambda$ while that of the weak country $F$ decreases in $\lambda$.

Proof of Proposition 3. Under the linear-symmetric contest success function, equation (5.3) can be rewritten as:

$$
\begin{aligned}
& {\left[\frac{1}{2}+\lambda\left(R_{H}^{*}-R_{F}^{*}\right)\right] \cdot \sigma \cdot\left(R_{H}^{*}+R_{F}^{*}\right) \geq R_{H}^{*}, } \\
\Leftrightarrow & \lambda \sigma\left[\left(R_{H}^{*}\right)^{2}-\left(R_{F}^{*}\right)^{2}\right]-(1-\sigma) R_{H}^{*} \geq \frac{\sigma\left(R_{H}^{*}-R_{F}^{*}\right)}{2} .
\end{aligned}
$$

Given the symmetry of the contest success function, equation (A.17) can be used to study under what conditions does the stronger or weaker ruler wish to initiate a war. 
Suppose in fact that $H$ is the stong ruler, namely $R_{H}^{*}>R_{F}^{*}$. Then equation (A.17) becomes:

$$
\lambda \sigma\left(R_{H}^{*}+R_{F}^{*}\right)-(1-\sigma) \frac{R_{H}^{*}}{R_{H}^{*}-R_{F}^{*}} \geq \frac{\sigma}{2} .
$$

Given the dependence of $\left(R_{H}^{*}, R_{F}^{*}\right)$ on $\lambda$ in Proposition 2, it is easy to see that the left-hand side increases in $\lambda$ over the range where $R_{H}^{*}, R_{F}^{*}<R_{c}$. Define $\lambda^{*}$ as the sensitivity at which $R_{H}^{*}=R_{c}$. Then, if $\lambda^{*} R_{c}>1 / 2$ there exists a $\widehat{\sigma}<1$ such that, for $\sigma \geq \widehat{\sigma}$, there exists a $\lambda_{1}<\lambda^{*}$ such that for $\lambda \geq \lambda_{1}$ condition (A.18) is met. If $\lambda^{*} R_{c}<1 / 2$ or $\sigma<\widehat{\sigma}$, then set $\lambda_{1}=\lambda^{*}$. Clearly, even though $\lambda_{1}<\lambda^{*}$, for $\lambda>\lambda^{*}$ the distance $R_{H}^{*}-R_{F}^{*}$ becomes smaller and smaller, so that at some point, when $\lambda$ becomes large, condition (A.18) is violated.

Suppose now that $F$ is the weak ruler, namely $R_{H}^{*}<R_{F}^{*}$. Then equation (A.17) becomes:

$$
\lambda \sigma\left(R_{F}^{*}+R_{H}^{*}\right)+(1-\sigma) \frac{R_{H}^{*}}{R_{F}^{*}-R_{H}^{*}} \leq \frac{\sigma}{2} .
$$

Given the dependence of $\left(R_{H}^{*}, R_{F}^{*}\right)$ on $\lambda$ in Proposition 2, it is easy to see that the left-hand side decreases in $\lambda$ over the range where $R_{H}^{*}, R_{F}^{*}<R_{c}$. When $\lambda=0$, the value of the left-hand side is finite. As a result, there exists a $\widehat{\sigma}<1$ such that, for $\sigma \geq \widehat{\sigma}$, there exists a $\lambda_{0}$ such that for $\lambda \leq \lambda_{0}$ condition (A.19) is met. For $\sigma<\widehat{\sigma}$, set $\lambda_{0}=0$.

We thus have seen that in $\lambda \in\left[0, \lambda_{0}\right] \cup\left[\lambda_{1}, \lambda^{*}\right]$ war occurs for sure and the optimal fiscal investments of Propositions 2 indeed characterize the full equilibrium. Suppose now that we are in $\lambda \in\left(\lambda_{0}, \lambda_{1}\right)$. Here our goal is not to fully derive the mixed-strategy equilibrium but describe how the equilibrium works. In this range, at the fiscal investments of Proposition 2 , countries have no incentive to go to war. How is an equilibrium determined in this case? Suppose first that for $\lambda \in\left(\lambda_{0}, \lambda_{1}\right)$ the equilibrium probability of war is $\omega=0$. In this case, countries go back to the autarky investments $\left(R_{F, \text { aut }}, R_{H, \text { aut }}\right)$. If at these investments no country has an incentive to go to war, then the equilibrium is one where for $\lambda \in\left(\lambda_{0}, \lambda_{1}\right)$ war does not occur and country behave as in autarky. It is easy to check that if this is the case, then $\lambda_{0}=0$. The logic is that, again by Proposition 2, state-building (and asymmetry among countries) fall in $\lambda$. As a result, if no ruler has an incentive to fight in autarky, when $\lambda=3 / 4 R_{J}$, aut , a fortiori no ruler has any incentive to fight for $\lambda=0$, for in this latter case countries are even more equal. In sum, if $\omega=0$, war only arises for $\lambda \in\left[\lambda_{1}, \lambda^{*}\right]$.

If instead at the autarky investments either ruler has an incentive to go to war, then in equilibrium the probability $\omega$ of going to war must be positive. Crucially, since autarky revenues are too high (and unequal) to avert war, it must be that a positive probability of war $(\omega>0)$ reduces state-building in the two countries, much in the spirit of Proposition 2 for $\lambda<3 / 4 R_{J, \text { aut }}$. From an ex ante standpoint, an overall probability of going to war of $\theta \omega$ induces (according to Proposition 2) optimal investments $\left[R_{F}^{*}(\lambda, \omega), R_{H}^{*}(\lambda, \omega)\right]$. The equilibrium is then reached by setting $\omega$ such that, at the equilibrium probability of $H$ winning $p\left(R_{F}^{*}(\lambda, \omega), R_{H}^{*}(\lambda, \omega)\right)$, the party who at autarky revenues is willing to attack is just indifferent between attacking or not (and thus willing to mix with probability $\omega$ ).

\section{B. INSTITUTIONS AND STATE BUILDING}

Consider the payoff implications of introducing institutions $\pi_{J}>0$. Given an amount of fiscal revenues $R_{J}=\kappa_{J} \cdot\left(A_{m}-A_{h}\right)$ collected in centralized districts, the total revenue accruing to the central ruler is now equal to $\widetilde{R}_{J}=\left(1-\pi_{J}\right) \cdot R_{J}$. The power holder of a centralized district now obtains $2 \pi_{J} \cdot\left(A_{m}-A_{h}\right)$ over two periods (which is equal to zero in the absence of institutions). As a result, the loss experienced by a power holder when his district is centralized is now equal to $2\left[\left(A_{l}-A_{h}\right)-\pi_{J} \cdot\left(A_{m}-A_{h}\right)\right]$.

The timing of the model is as follows: at the outset, each ruler chooses $\pi_{J}$; next, he sets centralization $\kappa_{J}$; finally, military and market interactions occur. To solve the model backwards, note that when, as assumed, $\pi_{J}<\widehat{\pi}_{J}$, one can replace $R_{J}$ with the ruler's effective tax revenue $\widetilde{R}_{J}=\left(1-\pi_{J}\right) \cdot R_{J}$ in the maximization problems (4.3) and (4.4). It is then easy to find that the cost for the ruler of raising $\widetilde{R}_{J}$ is equal to:

$$
C_{J}\left(\widetilde{R}_{J}\right)=\widetilde{c}_{J} \cdot \widetilde{R}_{J}^{2}, \text { where } \widetilde{c}_{J} \equiv \frac{1}{\widetilde{R}_{J, \text { aut }}},
$$

where, in the spirit of equation (3.8), we have:

$$
\widetilde{R}_{J, a u t}=\left(1-\pi_{J, a u t}\right) \cdot \min \left[\frac{\left(1-\pi_{J, a u t}\right)\left(A_{m}-A_{h}\right)^{2}}{B_{J}\left[\left(A_{l}-A_{h}\right)-\pi_{J, a u t} \cdot\left(A_{m}-A_{h}\right)\right]},\left(A_{m}-A_{h}\right)\right]
$$

where $\pi_{J, \text { aut }}$ is the strength of institutions set by the ruler in autarky.

Equation (B.2) shows that stronger institutions exert two conflicting effects on $\widetilde{R}_{J, \text { aut }}$ (i.e. on the inverse of the cost of centralization), one positive, one negative. As we discussed in the text, the case to consider is the one in which the first, positive effect dominates. Indeed, rulers will never set institutions in the decreasing range. This amounts to restricting 
institutions to the case $\pi_{J} \gtrless \vec{\pi}_{J}$, where $\vec{\pi}_{J}$ is the threshold below which the ruler's revenue increases in the strength of institutions. In this range, stronger institutions can simply be conceptualized as a factor reducing the marginal cost $\widetilde{c}_{J}$ of state-building. We assume, without loss of generality, that country $H$ is the low-cost country, namely $\widetilde{c}_{H} \leq \widetilde{c}_{F}$. This is the case when $H$ is sufficiently more cohesive than $F$ (i.e., $B_{H}<B_{F}$ ).

Under a linear contest function, and under the assumptions of Point (2-ii) in Proposition 2, the following result holds:

Proposition 4. Denote by $\pi_{J, \text { aut }}$ the equilibrium level of institutional upgrading by ruler $J=H, F$ in autarky and by $\widetilde{R}_{J, \text { aut }}$ and $\widetilde{c}_{J}$ the associated autarky revenues and marginal cost, respectively. Denote by $\kappa_{J}^{*}$ and $\pi_{J}^{*}$ the equilibrium levels of centralization and institutions prevailing in country $J$ when an external threat is present (i.e. for all $\theta>0$ ). We then have that:

(1) Institutions and centralization in country $J$ are stronger than in autarky if and only if $\lambda>3 \cdot \widetilde{c}_{J} / 4$.

(2) If centralization and institutions are partial, namely $\kappa_{J}^{*}<1$ and $\pi_{J}^{*}<\min \left(\vec{\pi}_{J}, \widehat{\pi}_{J}\right)$ for $J=H, F$, the less divided country has higher $\kappa_{J}^{*}$ and $\pi_{J}^{*}$ than its opponent.

Thus, institutions and centralization improve together as money sensitivity increases, and the more cohesive power reforms more aggressively, generating divergence. 27

Proof. The problem of the ruler when choosing how much to centralize is qualitatively identical to the one he faces in the absence of institutions, except that now institutions reduce the marginal cost of centralization. As a result, the ruler centralizes more when $\lambda$ is higher and centralizes more than in autarky when $\lambda>3 \cdot \widetilde{c}_{J} / 4$., where $\widetilde{c}_{J}$ is the marginal cost evaluated at the chosen level of institutions. Accordingly, the higher is $\lambda$ the higher is the divergence in centralization between the cohesive and the divided country.

Consider now the optimal choice of institutions. Because institutions are set before the centralization decision is taken, equations (4.3) and (4.4) imply that the value of institutions $\pi_{J}$ for the ruler of country $J$ is equal to:

$$
W_{J}\left(\pi_{J}, B_{J}\right)=\max _{R_{J}} \theta \cdot\left\{p_{J}\left(\widetilde{R}_{J}, \widetilde{R}_{-J}\right)\left(\widetilde{R}_{J}+\widetilde{R}_{-J}\right)-2 \widetilde{R}_{J}\right\}+2 \widetilde{R}_{J}-\frac{\widetilde{R}_{J}^{2}}{\widetilde{R}_{J, \text { aut }}},
$$

where $p_{J}\left(\widetilde{R}_{J}, \widetilde{R}_{-J}\right)$ is the probability with which the ruler of country $J$ wins the war. By the envelope theorem:

$$
\frac{d W_{J}\left(\pi_{J}, B_{J}\right)}{d \pi_{J}}=\frac{\left(\widetilde{R}_{J}^{*}\right)^{2}}{\widetilde{R}_{J, a u t}^{2}} \cdot \frac{d \widetilde{R}_{J, a u t}}{d \widetilde{c}_{J}},
$$

It is then easy to see that the marginal benefit of stronger institutions is higher when the ruler centralizes more. In particular, the marginal benefit of institutions is higher than in autarky if and only if the ruler's revenue is higher than in autarky. That is, if and only if $\lambda>3 \cdot \widetilde{c}_{J} / 4$, as stated in the proposition. Accordingly, institutions and centralization move together and the cohesive country has both stronger institutions and a more centralizes state than the divided country.

27. The intuition for why divided countries have a lower incentive to upgrade their institutions is that in these countries a marginal improvement in institutions appeases fewer opponents than in cohesive countries. This result is due to the uniform distribution of "political distance" $\beta$, recalling of course that we realistically assume that in all countries conflict is sufficiently strong that autarky centralization is partial (i.e. $\left.B_{J}>\left(A_{m}-A_{h}\right) /\left(A_{l}-A_{h}\right)\right)$ and that institutions are sufficiently weak that some conflict is present (i.e. $\left.\pi_{J}<\widehat{\pi}_{J}\right)$. 
REVIEW OF ECONOMIC STUDIES

C. ADDITIONAL REGRESSION RESULTS

TABLE C1

Battlefield results, battles without allies (dependent variable: dummy = 1 if richer power wins)

\begin{tabular}{|c|c|c|c|c|c|c|}
\hline & (1) & (2) & (3) & (4) & $\begin{array}{c}(5) \\
\text { Pre-1650 }\end{array}$ & $\begin{array}{c}(6) \\
\text { Post-1650 }\end{array}$ \\
\hline Diffrev & $\begin{array}{c}0.62^{* *} \\
(1.97)\end{array}$ & $\begin{array}{c}0.62^{* *} \\
(1.97)\end{array}$ & $\begin{array}{l}0.61^{* *} \\
(2.04)\end{array}$ & $\begin{array}{c}0.73^{* *} \\
(2.01)\end{array}$ & $\begin{array}{c}1.49 \\
(0.72)\end{array}$ & $\begin{array}{c}0.66^{*} \\
(1.73)\end{array}$ \\
\hline Diffpop & $\begin{array}{l}-0.090 \\
(-0.61)\end{array}$ & $\begin{array}{l}-0.090 \\
(-0.61)\end{array}$ & $\begin{array}{l}-0.13 \\
(-0.78)\end{array}$ & $\begin{array}{l}-0.25 \\
(-1.43)\end{array}$ & $\begin{array}{c}-0.050 \\
(-0.07)\end{array}$ & $\begin{array}{l}-0.31 \\
(-1.63)\end{array}$ \\
\hline naval & & & $\begin{array}{c}-0.20 \\
(-0.66)\end{array}$ & $\begin{array}{l}-0.38 \\
(-1.34)\end{array}$ & $\begin{array}{l}-0.64 \\
(-0.85)\end{array}$ & $\begin{array}{c}-0.51^{*} \\
(-1.69)\end{array}$ \\
\hline Constant & $\begin{array}{c}-0.32 \\
(-0.95)\end{array}$ & $\begin{array}{c}-0.32 \\
(-0.95)\end{array}$ & $\begin{array}{c}-0.21 \\
(-0.48)\end{array}$ & $\begin{array}{l}-1.27^{* * *} \\
(-5.08)\end{array}$ & $\begin{array}{l}-1.92^{* * *} \\
(-3.15)\end{array}$ & $\begin{array}{c}0.12 \\
(0.28)\end{array}$ \\
\hline$N$ & 182 & 182 & 182 & 179 & 22 & 157 \\
\hline
\end{tabular}

Note: $t$ statistics in parentheses. * $p<0.1, * * p<0.05, * * * p<0.01$.

TABLE C2

Heterogeneity and state-building (dependent variable: tax pressure)

\begin{tabular}{|c|c|c|c|c|}
\hline & (1) & (2) & (3) & (4) \\
\hline Sum & $\begin{array}{l}-1.515^{\text {*** }} \\
(-3.38)\end{array}$ & & & \\
\hline $\operatorname{Pred}_{1300}$ & & $\begin{array}{l}-0.283^{* *} \\
(-2.64)\end{array}$ & & \\
\hline Area & & & $\begin{array}{l}-4.21 e-12^{* * *} \\
(-4.50)\end{array}$ & \\
\hline Ethnic & & & & $\begin{array}{l}-19.24^{* * *} \\
(-3.1)\end{array}$ \\
\hline Constant & $\begin{array}{l}7.395^{* * *} \\
(6.67)\end{array}$ & $\begin{array}{l}10.48^{* * *} \\
(4.86)\end{array}$ & $\begin{array}{l}11.45^{\text {*** }} \\
(6.23)\end{array}$ & $\begin{array}{l}11.11^{\text {*** }} \\
(3.69)\end{array}$ \\
\hline$N$ & 53 & 53 & 53 & 53 \\
\hline$R^{2}$ & 0.363 & 0.249 & 0.402 & 0.125 \\
\hline
\end{tabular}

Note: Cf. Appendix E for data construction; $t$-statistics in parentheses; $* p<0.1, * * p<0.05, * * * p<0.01$. 
GENNAIOLI \& VOTH STATE CAPACITY AND MILITARY CONFLICT

D. ADDITIONAL FIGURE
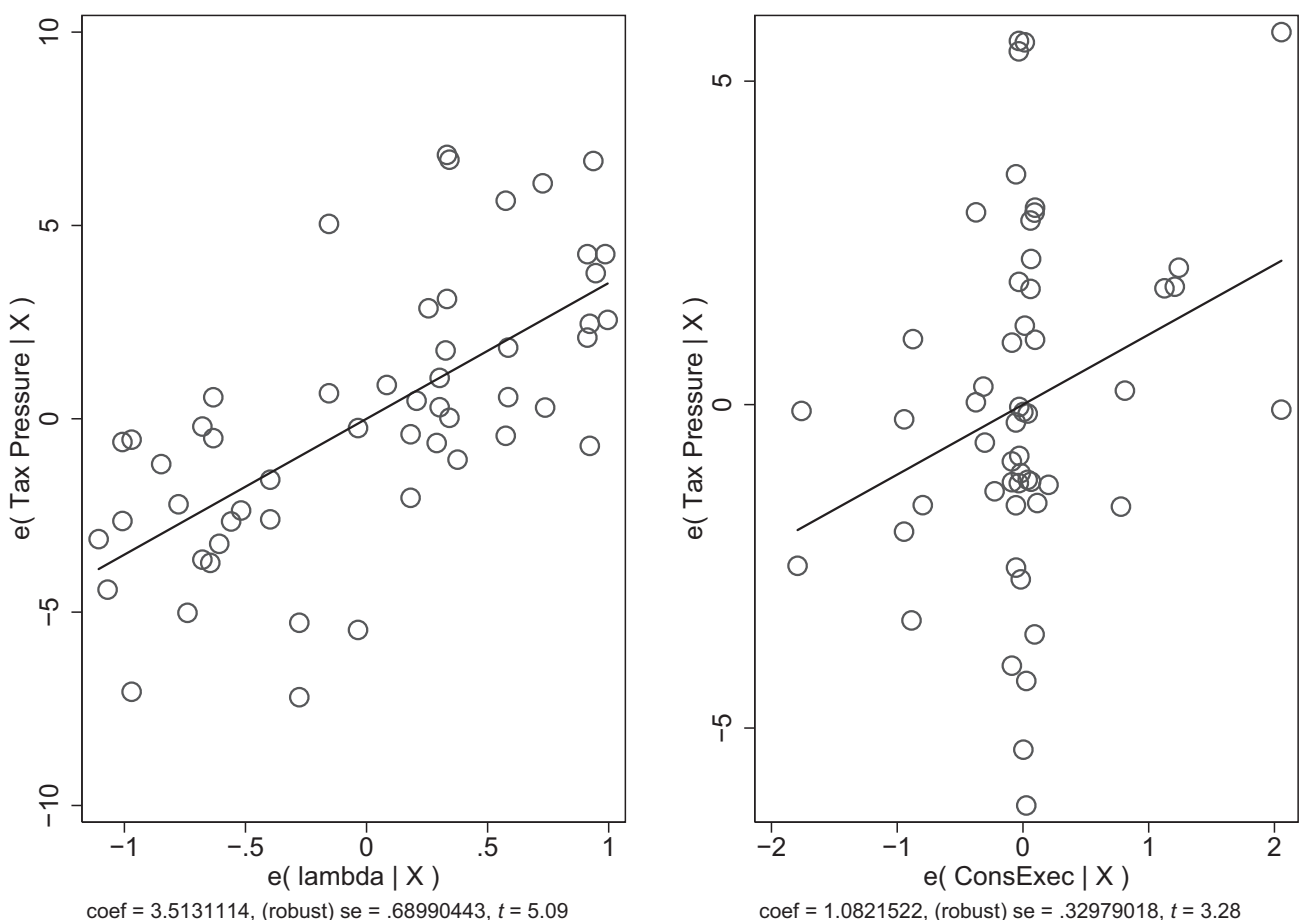

FIGURE D1

Fiscal capacity, money sensitivity, and institutions

Notes: The $y$-axis shows fiscal revenues per capita, as a multiple of the the country-specific daily wage rate. The left $x$-axis plots $\lambda$, the money-sensitivity of battlefield victories, controlling for other factors; the right one, constraints on the executive. 


\section{E. DATA}

Here, we detail the construction of the variables used in the empirical analysis.

\begin{tabular}{|c|c|}
\hline Variable & Description and Source \\
\hline BattleOutcome & $\begin{array}{l}\text { Dummy variable that takes the value of } 1 \text { if the fiscally stronger power wins (Landers, } \\
\text { 2003), and } 0 \text { otherwise. Battle data is from Jaques (2007). From these two sources, we } \\
\text { code the results of all battles fought on European soil from } 1500 \text { to } 1780 \text {. Excluding } \\
\text { sieges, civil conflicts and peasant revolts, this leaves } 374 \text { battles. Of these, } 80 \text { were } \\
\text { naval battles. }\end{array}$ \\
\hline Diffrev & $\begin{array}{l}\text { Log difference of tax pressure between richer and poorer power, calculated as Diffrev } \\
\quad=\ln \left(T P^{H}\right)-\ln \left(T P^{F}\right)\end{array}$ \\
\hline taxpressure & Annual tax revenue per head, scaled by urban wages. Source: Karaman and Pamuk (2010). \\
\hline$T P^{H}$ & Tax pressure in the richer power. Source: Karaman and Pamuk (2010). \\
\hline$T P^{F}$ & Tax pressure in the poorer power. \\
\hline RevenuеPC & Tax revenue per capita, in grams of silver per year. Source: Karaman and Pamuk (2010). \\
\hline Diffpop & $\begin{array}{l}\text { Log difference of population between richer and poorer power, calculated as Diffpop } \\
\quad=\ln \left(p^{H}\right)-\ln \left(p^{F}\right)\end{array}$ \\
\hline$p^{H}$ & $\begin{array}{l}\text { Population of richer power, in millions, at the beginning of the period to which the fiscal } \\
\text { data refers. Source: McEvedy and Jones (1978). }\end{array}$ \\
\hline$p^{F}$ & $\begin{array}{l}\text { Population of poorer power, in millions, at the beginning of the period to which the fiscal } \\
\text { data refers. Source: McEvedy and Jones (1978). }\end{array}$ \\
\hline Naval & Dummy variable for battles at sea. Source: Landers (2003). \\
\hline Allies & Dummy variable for engagements involving allies. Source: Jaques (2007). \\
\hline Pred 1300 & $\begin{array}{l}\text { The number of independent predecessor states on the territory of countries existing in } 1500 \\
\text { (using } 1500 \text { borders). Source: All figures are based on historical maps available at } \\
\text { www.euratlas.net. }\end{array}$ \\
\hline Ethnic & The ethnic fractionalization measure is taken from Alesina et al. (2003). \\
\hline Area & Total surface area as calculated in Q-GIS from the historical maps at www.euratlas.net. \\
\hline Sum & $\begin{array}{l}\text { Sum of three measure of heterogeneity: Pred } 1300, \text { Ethnic, and Area; variables } \\
\text { standardized so that each has mean }=0 \text { and st.dev. }=1 .\end{array}$ \\
\hline$\lambda$ & $\begin{array}{l}\text { Estimated money sensitivity of war outcomes-based on a regression of battle outcome } \\
\text { (BattleOutcome) on the Diffrev. }\end{array}$ \\
\hline
\end{tabular}

Acknowledgments. We received helpful comments from Philippe Aghion, Roland Benabou, Tim Besley, Francesco Caselli, Zhiwu Chen, Mark Dincecco, Patrick Francois, Regina Grafe, Avner Greif, Phil Hoffman, Peter Koudjis, Gerard Padro-i-Miquel, Roger Myerson, Nancy Qian, Torsten Persson, Jim Robinson, Enrico Spolaore, Jean Tirole, Mathias Thoenig, Nico Voigtländer, Pierre Yared, Fabrizio Zilibotti and from seminar participants at FU Amsterdam, IMT Lucca, CREI, U Penn, the NBER Summer Institute, the 2011 UAB-MOVE conference, the Toulouse CIFAR meeting, and the 2012 NBER Political Economy meeting. We thank the ERC for support through StG (\#241114 - Gennaioli) and AdG (\#230515 - Voth).

\section{Supplementary Data}

Supplementary data are available at Review of Economic Studies online.

\section{REFERENCES}

ACEMOGLU, D. (2005), "Politics and Economics in Weak and Strong States", Journal of Monetary Economics, 52, $1199-1226$.

ACEMOGLU, D., JOHNSON, S. and ROBINSON, J. A. (2001), "The Colonial Origins of Comparative Development: An Empirical Investigation", American Economic Review, 91, 1369-1401.

ACEMOGLU, D., JOHNSON, S. and ROBINSON, J. A. (2005), "The Rise of Europe: Atlantic Trade, Institutional Change, and Economic Growth", American Economic Review 95, 546-579.

ACEMOGLU, D. and ROBINSON, J. A. (2006), "Economic Backwardness in Political Perspective", American Political Science Review, 100, 115-131.

ALESINA, A., DEVLEESCHAUWER, A., EASTERLY, W., KURLAT, S. and WACZIARG, R. (2003), "Fractionalization", Journal of Economic Growth, 8, 155-194.

ALESINA, A. and LA FERRARA, E. (2005), Ethnic Diversity and Economic Performance. Journal of Economic Literature, 43, 762-800. 
ALESINA, A. and SPOLAORE, E. (2005), War, Peace, and the Size of Countries. Journal of Public Economics, 89, $1333-1354$.

ANDO, C. (2006). "The Administration of the Provinces", in D. S. Potter (ed.) A Companion to the Roman Empire. (Malden, MA: Blackwell Publishing Ltd) 175-192.

BESLEY, T. and PERSSON, T. (2009), "The Origins of State Capacity: Property Rights, Taxation, and Politics", American Economic Review, 99, 1218-1244.

BESLEY, T. and PERSSON, T. (2011), "Fragile States and Development Policy", Journal of the European Economic Association, 9, 371-398.

BONNEY, R. J. (1981), The King's Debts: Finance and Politics in France, 1589-1661. (Oxford: Oxford University Press).

BREWER, J. (1990), The Sinews of Power: War, Money and the English State, 1688-1783. (Harvard University Press).

CLARK, G. (2007). A Farewell to Alms: A Brief Economic History of the World (Princeton: Princeton University Press).

DELONG, J. B. and SHLEIFER, A. (1993), "Princes and Merchants: European City Growth before the Industrial Revolution", Journal of Law and Economics, 36, 671-702.

DINCECCO, M. (2009), "Fiscal Centralization, Limited Government, and Public Revenues in Europe, 1650-1913", The Journal of Economic History, 69, 48-103.

DINCECCO, M., FEDERICO, G. and VINDIGNI, A. (2011), "Warfare, Taxation, and Political Change: Evidence from the Italian Risorgimento", The Journal of Economic History, 71, 887-914.

DIXIT, A. (1987), "Strategic Behavior in Contests", American Economic Review, 77, 891-898.

ELLIOTT, J. H. (1963), Imperial Spain (London: Harper Collins).

EPSTEIN, S. R. (2002), Freedom and Growth: The Rise of States and Markets in Europe, 1300-1750. (London and New York: Routledge).

ERTMAN, T. (1997). Birth of the Leviathan: Building States and Regimes in Medieval and Early Modern Europe. (Cambridge University Press).

GREIF, A. (1993), "Contract Enforceability and Economic Institutions in Early Trade: The Maghribi Traders' Coalition", American Economic Review, 83, 525-548.

HAMILTON, E. J. (1934), American Treasure and the Price Revolution in Spain, 1501-1650. (Cambridge, MA: Harvard University Press).

HERBST, J. (2000), States and Power in Africa: Comparative Lessons in Authority and Control, (Princeton: Princeton University Press).

HIRAI, S. and SZIDAROVSZKY, F. (2013), "Existence And Uniqueness Of Equilibrium In Asymmetric Contests With Endogenous Prizes", International Game Theory Review, 15, 1-9.

HIRSHLEIFER, J. (1995), "Anarchy and its Breakdown”, Journal of Political Economy, 103, 26-52.

HOFFMAN, P. T. (2012), “Why was it Europeans Who Conquered the World?” Journal of Economic History, 72, 601-33.

HOFFMAN, P. T. and ROSENTHAL, J.-L. (1997), "The Political Economy of Warfare and Taxation in Early Modern Europe: Historical Lessons for Economic Development”, in J. N. Drobak and J. V. C. Nye (eds.) The Frontiers of the New Institutional Economics. (St. Louis, MO: Academic Press) 31-55.

HUANG, R. (1998), “The Ming fiscal administration”, in Denis C. Twitchett and Frederick W. Mote (eds.) The Cambridge History of China vol. 8. Part 2, 144-48.

HUI, V. T. (2005), War and State Formation in Ancient China and Early Modern Europe. (New York: Cambridge University Press).

JACKSON, M. O. and MORELLI, M. (2007), "Political Bias and War", American Economic Review, 97, 1353-1373.

JAQUES, T. (2007), Dictionary of Battles and Sieges: A Guide to 8,500 Battles from Antiquity through the 21st Century. (Westport, CA: Greenwood Press).

KARAMAN, K. K. and PAMUK, S. (2010), “Ottoman State Finances in European Perspective, 1500-1914”, Journal of Economic History, 70, 593-629.

KARAMAN, K. K. and PAMUK, S. (2013), "Different Paths to the Modern State in Europe: The Interaction between Warfare Economic Structure and Political Regime”, American Political Science Review, 107, 603-626.

KELLY, C. (2006). The Roman Empire: A Very Short Introduction. (Oxford University Press).

KUZMICS, H. and AXTMANN, R. (2007). Authority, State and National Character: The Civilizing Process in Austria and England, 1700-1900, Vol. 36. (Ashgate Publishing, Ltd).

LANDERS, J. (2003). The Field and the Forge: Population, Production, and Power in the Pre-industrial West. (New York: Oxford University Press).

LEE, S. J. (1991). The Thirty Years War. (Psychology Press).

LEVY, J. S. (1983), War in the Modern Great Power System, 1495-1975 (Lexington: University Press of Kentucky).

MARTIN, P., MAYER, T. and THOENIG, M. (2008), Make Trade Not War? Review of Economic Studies, 75, 865-900.

McEVEDY, C. and JONES, R. (1978), Atlas of World Population History. (London: Penguin).

NORDHOLT, H. S. (2010), The Spell of Power: A History of Balinese Politics, 1650-1940. (Brill).

NORTH, D. (1989). Institutions and Economic Growth: An Historical Introduction. World Development, 17, $1319-1332$.

PARKER, G. (1996), The Military Revolution: Military Innovation and the Rise of the West, 1500-1800 (Cambridge; New York: Cambridge University Press).

ROBERTS, M. (1956), The Military Revolution, 1560-1660: An Inaugural Lecture Delivered Before the Queen's University of Belfast. (Belfast: M. Boyd).

ROHNER, D., THOENIG, M. and ZILIBOTTI, F. (2013), "War Signals: A Theory of Trade, Trust, and Conflict", Review of Economic Studies, 80, 1114-1147. 
SKAPERDAS, S. (1992), "Cooperation, Conflict and Power in the Absence of Property Rights", American Economic Review, 82, 720-739.

SPOLAORE, E. and WACZIARG, R. (2009), "War and Relatedness”, (Working Paper No. 15095 NBER).

SZABO, F. A. (2013), The Seven Years War in Europe: 1756-1763 (London and New York: Routledge).

TICCHI, D. and VINDIGNI, A. (2008), "War and Endogenous Democracy", (discussion paper IZA).

TILLY, C. (1990), Coercion, Capital, and European States, AD 990-1990 (Studies in Social Discontinuity) (Cambridge: Blackwell).

VOIGTLÄNDER, N. and VOTH, H.-J. (2013), “The Three Horsemen of Riches: Plague, War and Urbanization in Early Modern Europe", Review of Economic Studies, 80, 774-811.

VRYONIS, S. (1969). The Byzantine Legacy and Ottoman Forms. Dumbarton Oaks Papers, 23/24, 251-308. 